\title{
Norisoboldine, a natural AhR agonist, promotes Treg differentiation and attenuates colitis via targeting glycolysis and subsequent $\mathrm{NAD}^{+} / \mathrm{SIRT} 1 / \mathrm{SUV} 39 \mathrm{H} 1 /$ H3K9me3 signaling pathway
}

\author{
Qi Lv' ${ }^{1}$ Kai Wang ${ }^{1}$, Simiao Qiao ${ }^{1}$, Ling Yang ${ }^{1}$, Yirong Xin ${ }^{1}$, Yue Dai ${ }^{1}$ and Zhifeng Wei ${ }^{1}$
}

\begin{abstract}
Norisoboldine (NOR), a natural aryl hydrocarbon receptor (AhR) agonist, has been demonstrated to attenuate ulcerative colitis (UC) and induce the generation of Treg cells. Under UC condition, hypoxia widely exists in colonic mucosa, and secondary changes of microRNAs (miRs) expressions and glycolysis contribute to Treg differentiation. At present, we worked for exploring the deep mechanisms for NOR-promoted Treg differentiation in hypoxia and its subsequent anti-UC action from the angle of AhR/miR or AhR/glycolysis axis. Results showed that NOR promoted Treg differentiation in hypoxia and the effect was stronger relative to normoxia. It activated AhR in $C D 4^{+} T$ cells under hypoxic microenvironment; CH223191 (a specific AhR antagonist) and siAhR-3 abolished NOR-promoted Treg differentiation. Furthermore, the progress of glycolysis, levels of Glut1 and HK2, and expression of miR-31 rather than miR-219 and miR-490 in CD4 ${ }^{+}$T cells were downregulated by NOR treatment under hypoxic microenvironment. However, HK2 plasmid but not miR-31 mimic significantly interfered NOR-enhanced Treg polarization. In addition, NOR reduced $\mathrm{NAD}^{+}$and SIRT1 levels, facilitated the ubiquitin-proteasomal degradation of SUV39H1 protein, and inhibited the enrichment of H3K9me3 at $-1,201$ to $-1,500$ region of Foxp3 promoter in $\mathrm{CD}^{+}{ }^{+} \mathrm{T}$ cells under hypoxic microenvironment, which was weakened by HK2 plasmid, $\mathrm{CH} 223191$, and siAhR-3. Finally, the correlation between NOR-mediated activation of AhR, repression of glycolysis, regulation of NAD $/$ SIRT1/SUV39H1/H3K9me3 signals, induction of Treg cells, and remission of colitis was confirmed in mice with DSS-induced colitis by using $\mathrm{CH} 223191$ and HK2 plasmid. In conclusion, NOR promoted Treg differentiation and then alleviated the development of colitis by regulating AhR/glycolysis axis and subsequent NAD $/$ SIRT1/SUV39H1/H3K9me3 signaling pathway.
\end{abstract}

\section{Introduction}

Regulatory $\mathrm{T}$ (Treg) cells are a unique subpopulation of $\mathrm{CD} 4^{+} \mathrm{T}$ cells, which have pivotal roles in maintenance of

\footnotetext{
Correspondence: Yue Dai (yuedaicpu@126.com) or

Zhifeng Wei (1020132346@cpu.edu.cn)

${ }^{1}$ Department of Pharmacology of Chinese Materia Medica, School of

Traditional Chinese Pharmacy, China Pharmaceutical University, 24 Tong Jia Xiang, Nanjing 210009, China

These contributed equally to this work: Qi Lv, Kai Wang.

Edited by $\mathrm{H}-\mathrm{U}$ Simon
}

immune tolerance and prevention of autoimmunity against self-antigens. Treg cells can inhibit the proliferation and activation of T-effector (Teff) cells by cell-cell contact or secretion of transforming growth factor (TGF) $\beta$, interleukin (IL)-10, granzyme, and perforin ${ }^{1,2}$. The deficiency of Treg cells has been linked to the occurrence and development of multiple autoimmune diseases in animals and humans, and adoptive transfer of Treg cells shows opposite 
effect. Therefore, boosting numbers of Treg cells is likely to be an effective strategy for the treatment of immunerelated diseases including ulcerative colitis (UC), experimental autoimmune encephalomyelitis, etc.

The detailed mechanisms for Treg differentiation are still obscure and recent evidences suggest that hypoxia has an important role $^{3}$. In response to hypoxia, the expressions of microRNAs (miRs) change and glycolytic switch occurs. Under hypoxic microenvironment, the expression of miR-31 in dendritic cells (DCs) is elevated and the expression of miR-1296 in hepatocellular carcinoma tissue is reduced ${ }^{4,5}$. Notably, miR-212/132 cluster knockout mice show high percentage of IL-10-producing $\mathrm{CD}^{+}{ }^{+} \mathrm{T}$ cells in colons ${ }^{6}$. In addition, miR-31, miR-219, and $m i R-490$ can bind with $3^{\prime}$-untranslated region of Foxp3 gene to regulate Treg differentiation ${ }^{7}$. Similarly, hypoxia contributes to switching the metabolism from oxidative phosphorylation to aerobic glycolysis in multiple kinds of cells, evidenced by increased production of metabolic acids ${ }^{8}$. 3-Bromopyruvate, a specific inhibitor of glycolysis, significantly decreases the arthritis scores of SKG mice by inducing Treg cells generation ${ }^{9}$. In parallel, 2-deoxy-D-glucose promotes the expression of Foxp3 under Treg -polarization condition ${ }^{10}$.

UC is a chronic inflammatory disorder of the colonic mucosa, which starts in the rectum and generally extends proximally in a continuous manner through part of, or the entire colon ${ }^{11}$. A robust hypoxia happens, because that profound neutrophils and macrophages infiltrating in colons require abundant oxygen to maintain growth, proliferation, apoptosis, and die $^{12}$. Karhausen and colleagues. ${ }^{13}$ report the presence of hypoxia in colons by using 2-(2nitro-1H-imidazol-1yl)-N-(2, 2, 3, 3,-pentafluoropropyl) acetamide to measure tissue oxygenation of colitis mice; Choi and colleagues. ${ }^{14}$ demonstrate that inflammatory hypoxia is observed in colons of mice with chronic colitis. Norisoboldine (NOR), the primary isoquinoline alkaloid of Radix Linderae, possesses well ability to activate aryl hydrocarbon receptor $(\mathrm{AhR})^{15}$. In addition, it can effectively inhibit systemic inflammation in rats with adjuvantinduced arthritis or collagen-induced arthritis through a gut-dependent manner ${ }^{16}$. Subsequently, we demonstrate that NOR significantly alleviates colitis in dextran sulfate sodium (DSS)-induced mice and upregulates percentages of Treg cells in colons ${ }^{17}$. However, the detailed mechanisms are still enigmatic and need further investigation. At present, we explored the mechanisms for NOR-promoted Treg differentiation and subsequent anti-UC effect from the angle of miRs and glycolysis in hypoxia.

\section{Results}

NOR promotes the differentiation of Treg cells in hypoxia

In our previous study, NOR has been demonstrated to alleviate colitis in mice, which was accompanied with elevated percentages of Treg cells in colons ${ }^{17}$. However, the detailed mechanisms remain unknown. Recently, articles indicate that hypoxia widely exists in colonic mucosa and contribute to the differentiation of Treg cells ${ }^{12,18}$. Therefore, we first detected the effect of NOR on Treg differentiation in hypoxia.

To exclude the interference of cytotoxicity on the action of NOR, viability of $\mathrm{CD}^{+} \mathrm{T}$ cells was tested. At the concentration below $60 \mu \mathrm{M}$, NOR did not exhibit obvious cytotoxicity of $\mathrm{CD} 4^{+} \mathrm{T}$ cells (Fig. 1a). Results of flow cytometry analysis revealed that the minimum effective concentration of NOR-promoted Treg differentiation in hypoxia was $3 \mu \mathrm{M}$, whereas in normoxia it was $10 \mu \mathrm{M}$. Of note, NOR $(30 \mu \mathrm{M})$ increased the frequencies of Treg cells to $9.27 \%$ in hypoxia and $6.71 \%$ in normoxia (Fig. 1b). In parallel, similar results were observed on levels of Foxp3 and IL-10 (Supplementary Figure $1 \mathrm{a}$ and $\mathrm{b}$ ).

The findings suggested that NOR could promote Treg differentiation in hypoxia and normoxia. The minimum effective concentration was lower and the action was stronger at the same concentration in hypoxia than normoxia. Subsequently, mechanisms for NOR-promoted Treg differentiation in hypoxia were explored.

\section{NOR induces the activation of AhR in hypoxia}

Data indicate that AhR is favorable for Treg differentiation and NOR has been identified as a possible AhR agonist $^{15,19}$. Therefore, the participation of AhR in NORmediated promotion of Treg differentiation under hypoxic microenvironment was determined. 2, 3, 7, 8Tetrachlorodibenzo-p-dioxin (TCDD) is a classical AhR agonist and can promote Treg differentiation in normoxia. To compare and find out the similarities and differences between NOR and classical AhR agonist in Treg differentiation under hypoxic microenvironment, TCDD was adopted as a positive drug.

In Fig. 2a, all the three pairs of siAhR inhibited AhR expression and siAhR-3 showed the best efficiency. Furthermore, NOR $(30 \mu \mathrm{M})$ significantly enriched Treg differentiation in hypoxia, siAhR-3 and CH223191 $(10 \mu \mathrm{M})$ dramatically prevented the action (Fig. 2b). Consistently, siAhR-3 and CH223191 significantly weakened NORinduced expressions of Foxp3 and IL-10 in CD4 ${ }^{+} \mathrm{T}$ cells under hypoxic microenvironment (Supplementary Figure $2 a$ and $b$ ).

The effect of NOR on AhR activation in $\mathrm{CD}^{+} \mathrm{T}$ cells under hypoxic microenvironment has not been demonstrated and the following experiments were performed. Results of liquid chromatography-mass spectrometry (LC-MS) showed that NOR could enter into cytoplasm of $\mathrm{CD}^{+}{ }^{+} \mathrm{T}$ cells (Fig. 2c). Moreover, NOR $(10,30 \mu \mathrm{M})$ and TCDD ( $5 \mathrm{nM})$ facilitated the disassociation of HSP90/ 

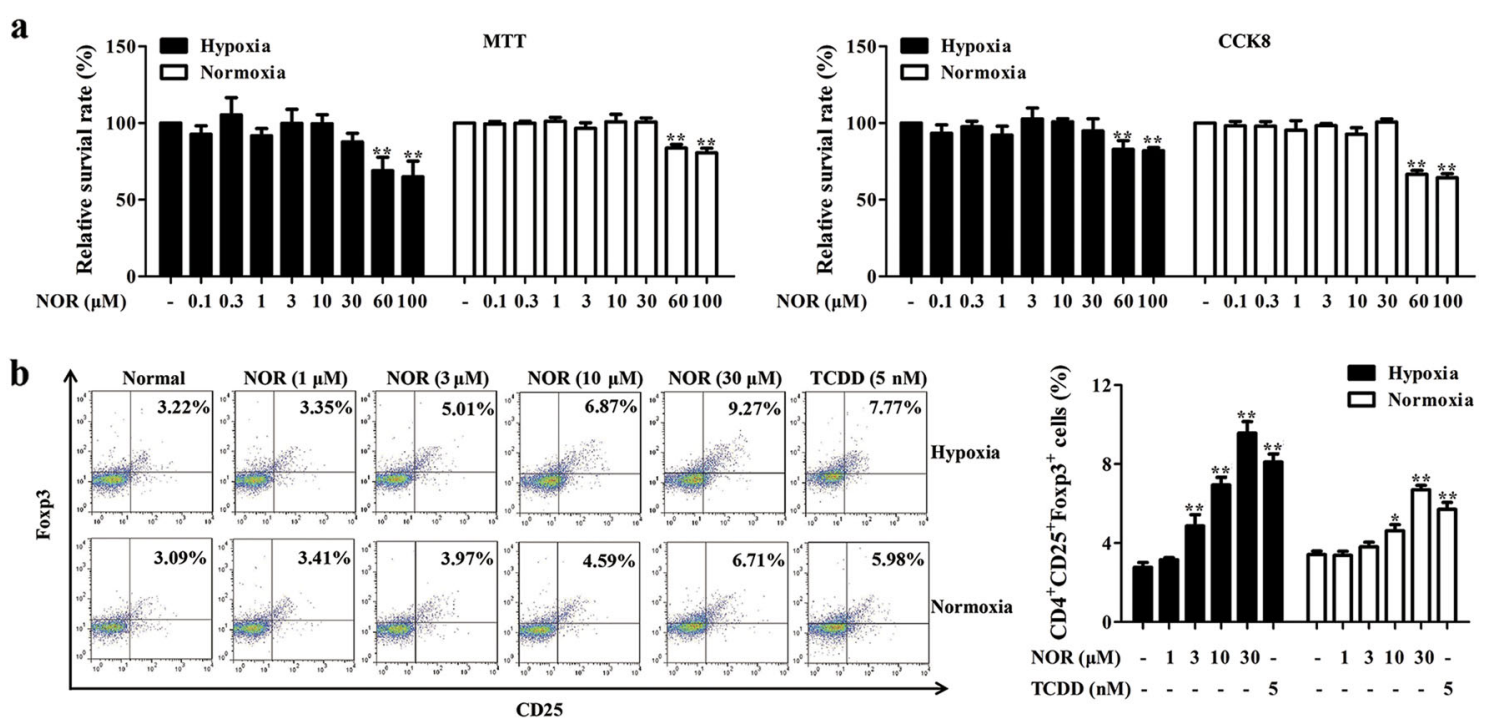

Fig. 1 NOR promotes Treg differentiation under hypoxic and normoxic microenvironment. a CD4 ${ }^{+} \mathrm{T}$ cells were cultured with NOR $(0.1,0.3,1$, $3,10,30,60,100 \mu \mathrm{M})$ in hypoxia or normoxia for $72 \mathrm{~h}$ and cell viability was analyzed by MTT and CCK-8. $\mathbf{b}$ CD $4^{+} \mathrm{T}$ cells were cultured with anti-CD3/ CD28 $(2 \mu \mathrm{g} / \mathrm{mL})$, NOR $(1,3,10,30 \mu \mathrm{M})$, and TCDD $(5 \mathrm{nM})$ in hypoxia or normoxia for $72 \mathrm{~h}$, and frequencies of Treg cells were analyzed by flow cytometry. Data were expressed as means \pm SEM of three independent experiments. ${ }^{*} P<0.05,{ }^{* *} P<0.01$ vs. Normal group

AhR complexes, the nuclear translocation of AhR, and the formation of AhR/ARNT complexes. Lastly, the activity of xenobiotic response element (XRE)-luciferase reporter gene, expressions and enzyme activity of CYP1A1 were also elevated (Fig. 2d-i). These results indicated that NOR drove Treg cells abundance in an AhR-dependent manner under hypoxic microenvironment.

\section{NOR-promoted Treg differentiation is independent of miRs in hypoxia}

The miRs represent a class of evolutionarily conserved regulatory RNAs, which modulate gene expressions including Foxp $3^{20}$. In hypoxia, expressions of multiple miRs change and the miRs function as key mediators for the action of AhR activation. Furthermore, 3, 3'-diindolylmethane (DIM) and indole-3-carbinol (I3C), the classical AhR agonists, promote Treg differentiation by targeting miR-31, $m i R-219$, and $m i R-490^{4,5,7}$.

Thus, quantitative-PCR (Q-PCR) assay was performed to assess effect of NOR on mRNA expressions of $m i R-31$, $m i R-219$, and $m i R-490$ in $C D 4^{+} \mathrm{T}$ cells. In Fig. 3a, NOR $(10,30 \mu \mathrm{M})$ significantly downregulated mRNA expression of $m i R-31$, but not $m i R-219$ and $m i R-490$ in $\mathrm{CD}^{+}$ $\mathrm{T}$ cells under hypoxic atmosphere. However, $m i R-31$ mimic showed little effect of NOR-promoted Treg differentiation (Fig. 3b, c), expressions of Foxp3 and IL-10 (Supplementary Figure $3 \mathrm{a}$ and b) in hypoxia. These interesting results indicated that NOR-induced generation of Treg cells in hypoxia was independent of miR-31.

\section{NOR enhances Treg polarization via a glycolysis-} dependent manner in hypoxia

Glycolysis is a metabolic pathway that catabolizes glucose to induce the generation of lactate. Data reveal that glycolysis in cells is strengthened in hypoxia and blocking it promotes Treg differentiation ${ }^{9,10}$. Herein, effect of NOR on glycolysis in $\mathrm{CD} 4^{+} \mathrm{T}$ cells was measured. $\mathrm{NOR}(3,10$, $30 \mu \mathrm{M})$ and TCDD $(5 \mathrm{nM})$ markedly restrained the uptake of 2-[N-(7-nitrobenz-2-oxa-1, 3-diazol-4-yl) amino]-2deoxy-D-glucose (2-NBDG), consumption of glucose, and production of lactate in $\mathrm{CD}^{+} \mathrm{T}$ cells under hypoxic atmosphere (Fig. $4 \mathrm{a}-\mathrm{c}$ ). However, $\operatorname{NOR}(3,10,30 \mu \mathrm{M})$ and TCDD $(5 \mathrm{nM})$ did not influence glycolysis in $\mathrm{CD}^{+}$ $\mathrm{T}$ cells under normoxic atmosphere (Supplementary Figure $4 a-c)$.

The progress of glycolysis is controlled by serials of enzymes, including hexokinase II (HK2), phosphoglucoisomerase, phosphofructokinase (PFK), glyceraldehyde 3phosphatedehydrogenase (GAPDH), phosphaglycerate kinase, phosphoglycerate mutase, triosephosphate isomerase (TPI), enolase (Eno1), Aldolase, lactate dehydrogenase (LDH), and pyruvate kinase M (PKM). Notably, Glut1 is the selectively glucose transporter of $\mathrm{T}$ cells, HK2, PFK, and PKM are the rate-limiting enzymes in glycolysis $^{21}$. Specially, expressions of TPI, Eno1, Aldolase, and PKM are increased in colonic mucosa of UC patients. To verify which enzyme contributes to NOR-depressed glycolysis in CD4 ${ }^{+} \mathrm{T}$ cells, the levels of Glut1, HK2, TPI, Eno1, Aldolase, PFK, and PKM were determined. NOR (3, $10,30 \mu \mathrm{M})$ and TCDD $(5 \mathrm{nM})$ gradually reduced mRNA 


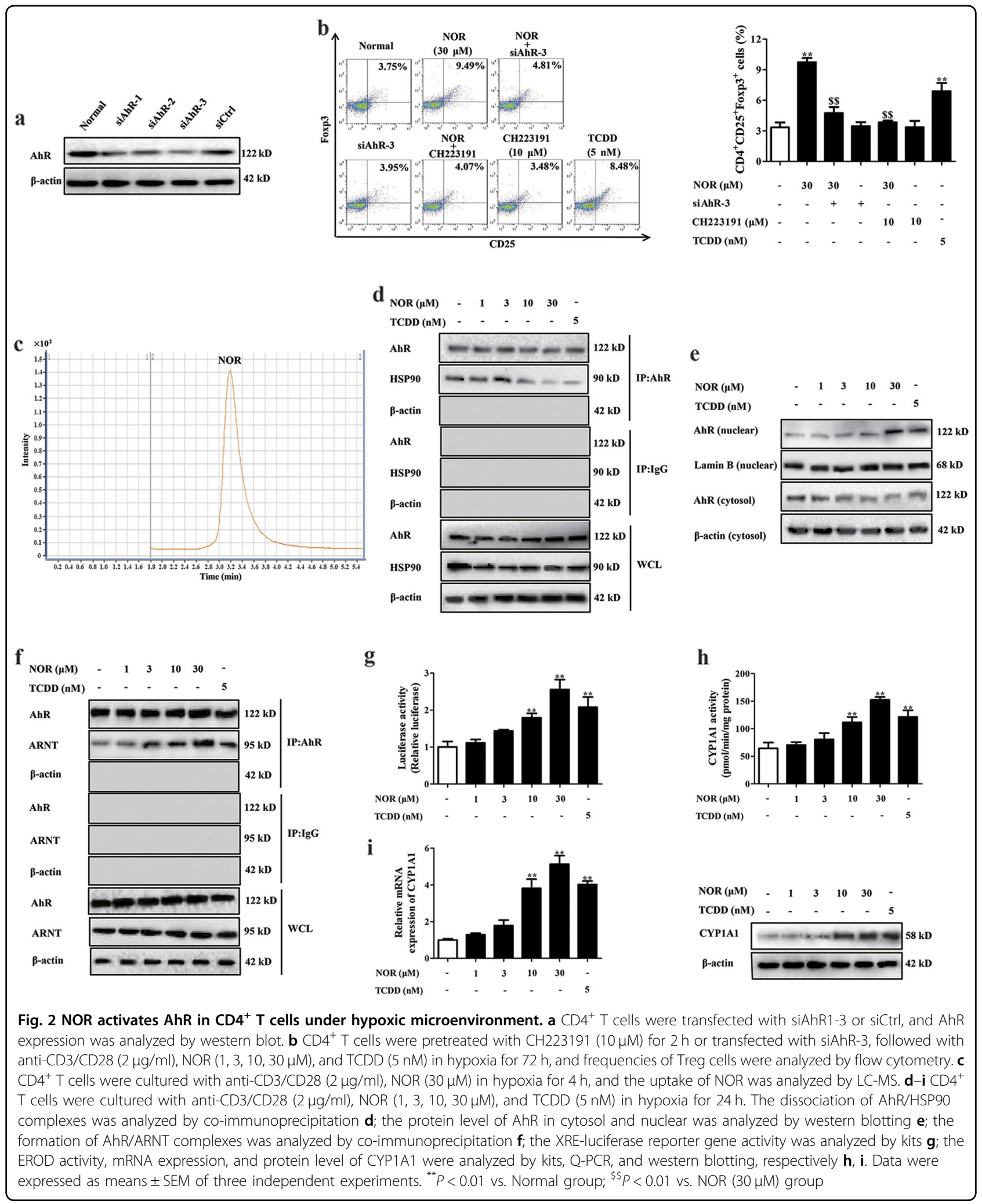

and protein levels of Glut1 and HK2 in CD4 $4^{+} \mathrm{T}$ cells, and the reduction was more prominent on level of HK2 (Fig. 4d, e). Conversely, the expressions of Glut1, HK2,
TPI, Eno1, Aldolase, PFK, and PKM were not affected by NOR $(3,10,30 \mu \mathrm{M})$ and TCDD $(5 \mathrm{nM})$ in normoxia (Supplementary Figure $4 \mathrm{~d}$ and e). 
a

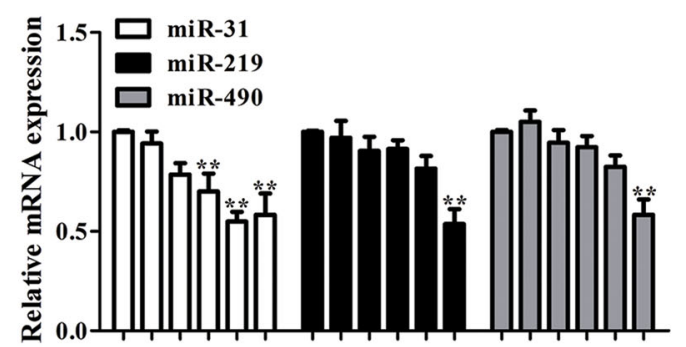

$\operatorname{NOR}(\mu \mathrm{M}) \quad-131030-\quad-131030-\quad-131030-$

TCDD (nM) - $\quad \ldots-5 \quad \ldots-\ldots$

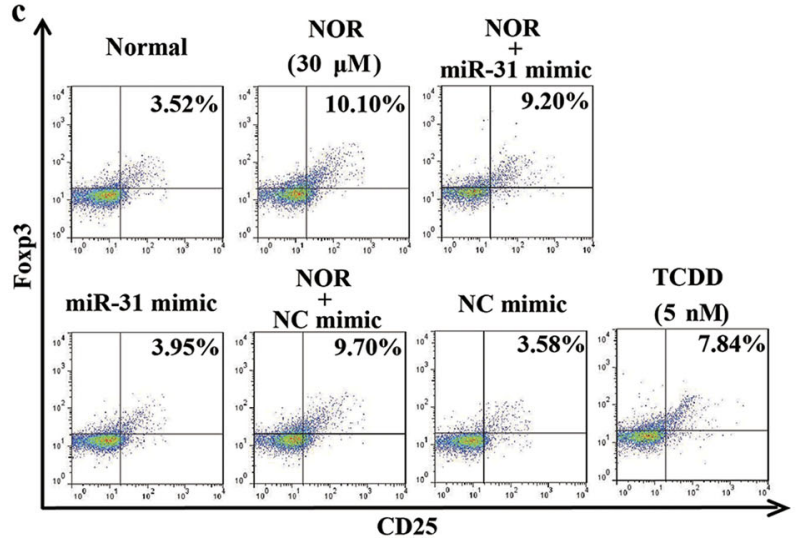

b
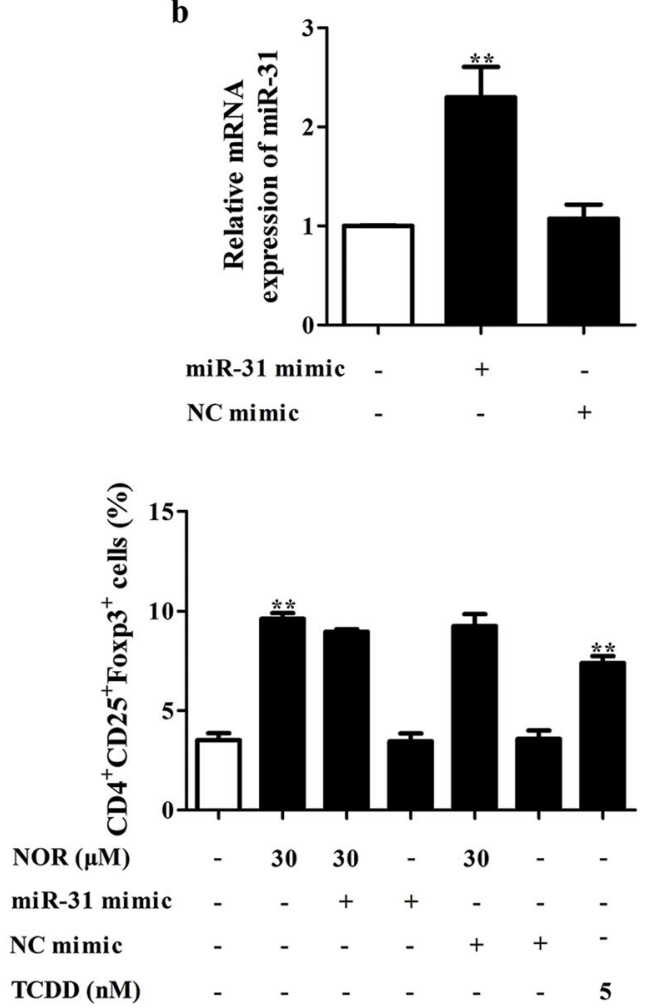

Fig. 3 NOR-promoted Treg differentiation is independent of miRs under hypoxic microenvironment. a CD4 ${ }^{+} \mathrm{T}$ cells were cultured with antiCD3/CD28 $(2 \mu \mathrm{g} / \mathrm{ml})$, NOR $(1,3,10,30 \mu \mathrm{M})$, and TCDD $(5 \mathrm{nM})$ in hypoxia for $24 \mathrm{~h}$. The mRNA expressions of miR-31, miR-219, and miR-490 were analyzed by Q-PCR. $\mathbf{b}$ CD4 ${ }^{+} \mathrm{T}$ cells were transfected with miR-31 or NC mimic and mRNA expression of miR-31 was analyzed by Q-PCR. $\mathbf{c} C D 4^{+} \mathrm{T}$ cells were transfected with miR-31 or NC mimic, followed with incubation of anti-CD3/CD28 $(2 \mu \mathrm{g} / \mathrm{ml})$, NOR $(30 \mu \mathrm{M})$, and TCDD $(5 \mathrm{nM})$ in hypoxia for $72 \mathrm{~h}$, and frequencies of Treg cells were analyzed by flow cytometry. Data were expressed as means \pm SEM of three independent experiments. ${ }^{* *} P<0.01$ vs. Normal group

Increasing evidence indicates that HK2 but not Glut1 is required for Treg differentiation in vitro and in vivo, 90,21 . More importantly, NOR showed stronger reduction of HK2 level relative to Glut1. Therefore, HK2 plasmid was applied to verify the participation of glycolysis in NOR-mediated Treg polarization under hypoxic microenvironment. However, NOR-induced Treg differentiation was not affected by HK2 plasmid in normoxia (Supplementary Figure 4f-h). As expected, HK2 plasmid significantly weakened NOR $(30 \mu \mathrm{M})$-promoted Treg differentiation (Fig. 4f, g), expressions of Foxp3 and IL-10 in hypoxia (Supplementary Figure 5a and b). Further results showed that siAhR-3 and $\mathrm{CH} 223191(10 \mu \mathrm{M})$ almost completely restored NOR-inhibited glycolysis of $\mathrm{CD}^{+} \mathrm{T}$ cells in hypoxia (Fig. $4 \mathrm{~h}-\mathrm{k}$ ).

Considering that HIF- $1 \alpha$ ubiquitously expresses in hypoxia, HK2 and Glut1 are demonstrated as target genes of HIF- $1 \alpha$, the following experiments were performed, and $\operatorname{NOR}(1,3,10,30 \mu \mathrm{M})$ and TCDD (5 nM) barely influenced the level of HIF-1 $\alpha$, whereas it remarkably downregulated the formation of HIF-1 $\alpha /$ ARNT complexes in hypoxia (Supplementary Figure 6a and b). All these results might imply that NOR reduced expressions of HK2 and Glut1, and glycolysis by inhibiting the formation of HIF-1 $\alpha /$ ARNT complexes in CD $4^{+} \mathrm{T}$ cells under hypoxic microenvironment.

\section{NOR decreases the levels of $\mathrm{NAD}^{+}$and SIRT1 in hypoxia}

Then, the precise mechanisms responsible for NORpromoted Treg differentiation after repression of glycolysis were explored. It is well established that nicotinamide adenine dinucleotide $\left(\mathrm{NAD}^{+}\right)$level increases accompanied with the progress of glycolysis and drives the shift of Treg cells toward Th17 cells $^{22,23}$. Here, NOR $(3,10,30 \mu \mathrm{M})$ and TCDD $(5 \mathrm{nM})$ significantly decreased $\mathrm{NAD}^{+}$level in $\mathrm{CD}^{+}{ }^{+} \mathrm{T}$ cells and the effect was diminished by HK2 plasmid, CH223191 (10 $\mu \mathrm{M})$, and siAhR-3 (Fig. 5a-c).

Importantly, $\mathrm{NAD}^{+}$has been demonstrated as the substrate and agonist of sirtuins (SIRTs). SIRT1 and SIRT2 are localized at the nucleus and cytoplasm, and possess the deacetylase activity ${ }^{24}$. Considering that the 

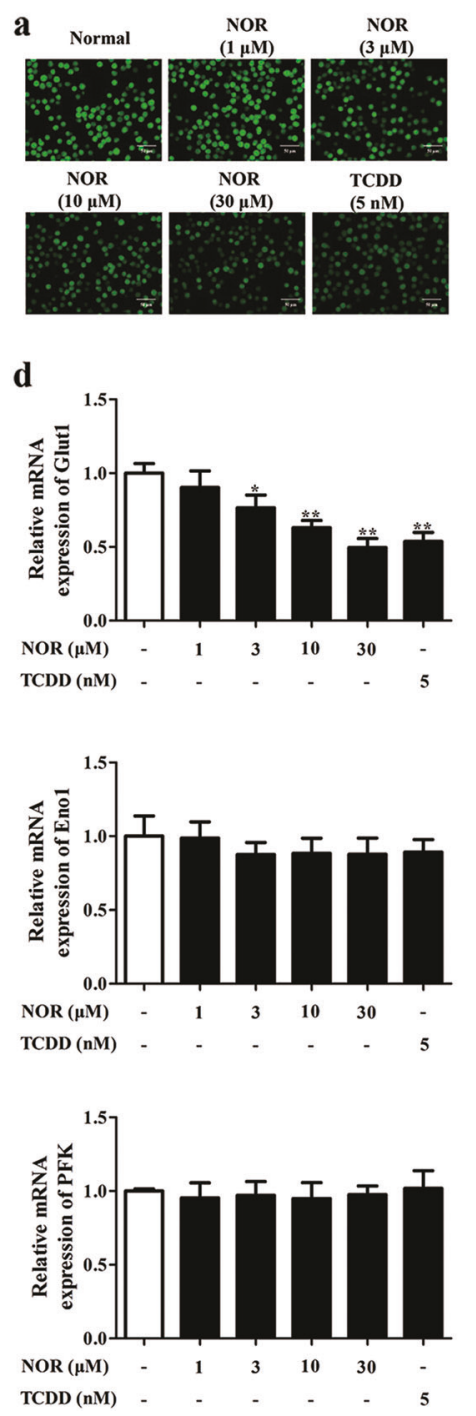
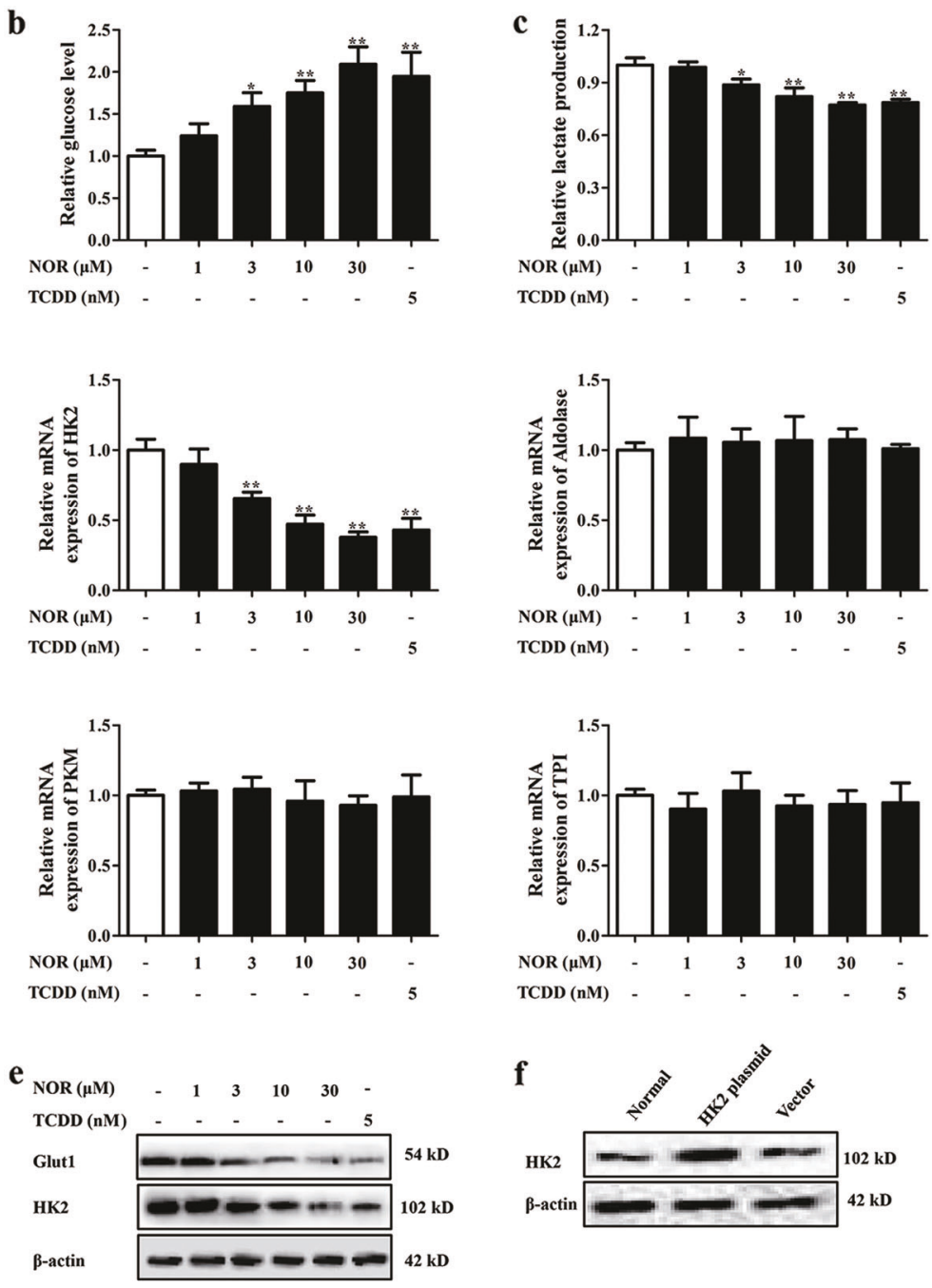

Fig. 4 (See legend on next page.)

process of glycolysis occurs in the cytoplasm, mRNA expressions of SIRT1 and SIRT2 were detected. NOR (3, $10,30 \mu \mathrm{M})$ and TCDD (5 nM) significantly decreased the mRNA expression of SIRT1 in $\mathrm{CD}^{+} \mathrm{T}$ cells under hypoxic microenvironment, but not SIRT2 (Fig. 5d). Consistently, the protein level of SIRT1 was also markedly reduced (Fig. 5e). Furthermore, NOR-decreased SIRT1 expression in $\mathrm{CD}^{+} \mathrm{T}$ cells under hypoxic microenvironment was recused by $\mathrm{HK} 2$ plasmid, $\mathrm{CH} 223191$ $(10 \mu \mathrm{M})$, and siAhR-3 (Fig. 5f, g).

NOR facilitates the ubiquitin-proteasomal degradation of SUV39H1 in hypoxia

Data indicate that SIRT1 drives the abundance of Treg cells by directly regulating the acetylation level of Foxp3 protein $^{25}$. However, NOR elevated both protein and
mRNA levels of Foxp3 in CD4 ${ }^{+} \mathrm{T}$ cells. Therefore, we supposed that SIRT1 had an indirect role in NORpromoted Treg differentiation. Multiple studies demonstrate that SIRT1 can directly regulate the expressions of histone methyltransferases (KMTs) and histone demethylases (KDMs), which are altered in hypoxia, including MLL1, G9a, SUV39H1, JMJD3, and EZH2 ${ }^{26-33}$. Therefore, effects of NOR and TCDD on protein levels of MLL1, SUV39H1, G9a, EZH2, and JMJD3 were detected.

$\operatorname{NOR}(3,10,30 \mu \mathrm{M})$ and TCDD $(5 \mathrm{nM})$ remarkably reduced the protein level of SUV39H1, whereas the others remained unchanged (Fig. 6a). Next, to further confirm the impact of NOR and TCDD on SUV39H1, Q-PCR assay was adopted. Unfortunately, $\operatorname{NOR}(3,10,30 \mu \mathrm{M})$ and TCDD (5 nM) scarcely influenced mRNA expression 
g

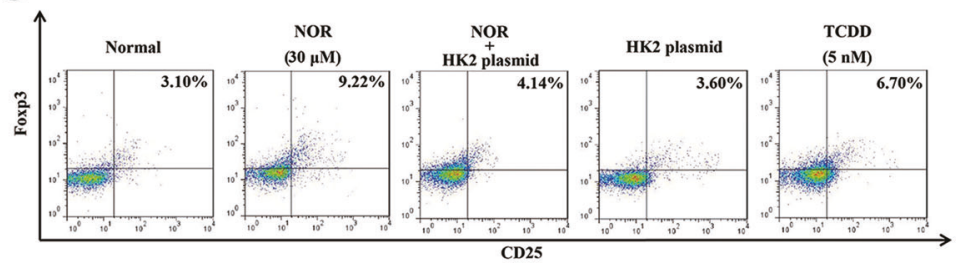

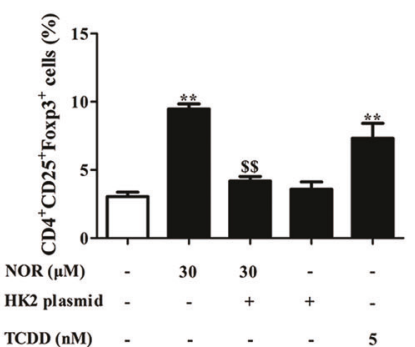

j

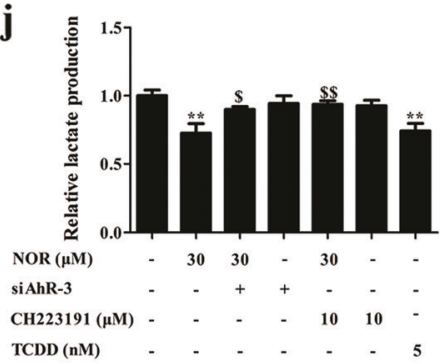

$\operatorname{TCDD}(\mathrm{nM})$

$\mathbf{k}$
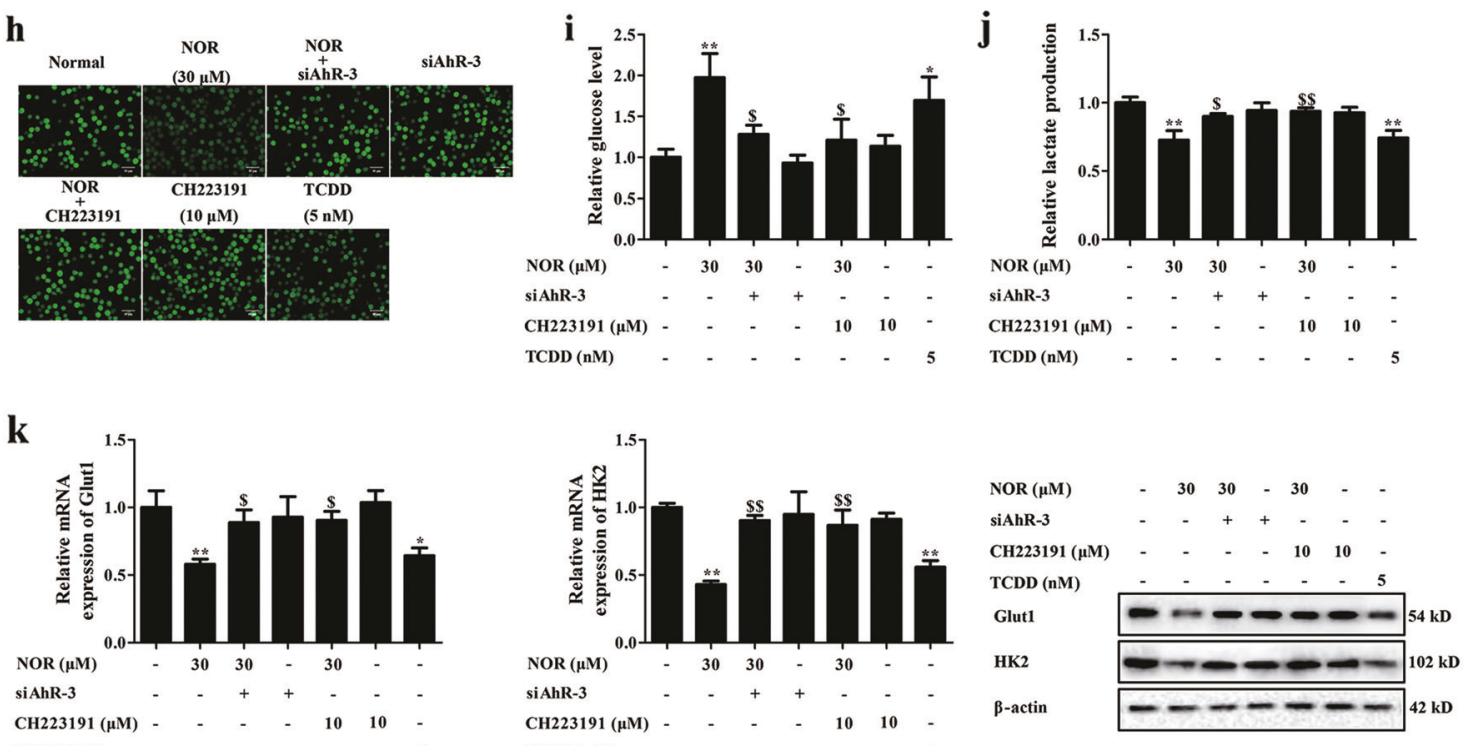

Fig. 4 NOR enhances Treg polarization via a glycolysis-dependent manner under hypoxic microenvironment. a-e $\mathrm{CD} 4^{+} \mathrm{T}$ cells were cultured with anti-CD3/CD28 $(2 \mu \mathrm{g} / \mathrm{ml})$, NOR $(1,3,10,30 \mu \mathrm{M})$, and TCDD $(5 \mathrm{nM})$ in hypoxia for $24 \mathrm{~h}$. Glucose uptake was analyzed by immunofluorescence and the images were taken at $\times 200$ magnification (scale bar: $50 \mu \mathrm{m}$ ) a; glucose consumption was analyzed by kits $\mathbf{b}$; lactate production was analyzed by kits c; mRNA expressions of Glut1, HK2, Aldolase, Eno1, PKM, TPI, and PFK were analyzed by Q-PCR $\mathbf{d}$; protein levels of Glut1 and HK2 were analyzed by western blotting e. $\mathbf{f} \mathrm{CD}_{4}{ }^{+} \mathrm{T}$ cells were transfected with HK2 plasmid or vector and protein level of HK2 was detected by western blotting. $\mathbf{g}$ CD4 ${ }^{+}$ T cells were transfected with HK2 plasmid, followed with incubation of anti-CD3/CD28 $(2 \mu \mathrm{g} / \mathrm{ml})$, NOR $(30 \mu \mathrm{M})$, and TCDD (5 nM) in hypoxia for $72 \mathrm{~h}$, and frequencies of Treg cells were analyzed by flow cytometry. $\mathbf{h}-\mathbf{k}$ CD4 $4^{+} \mathrm{T}$ cells were pretreated with $\mathrm{CH} 223191(10 \mu \mathrm{M})$ for $2 \mathrm{~h}$ or transfected with siAhR-3, followed with incubation of anti-CD3/CD28 $(2 \mu \mathrm{g} / \mathrm{ml})$, NOR $(30 \mu \mathrm{M})$, and TCDD $(5 \mathrm{nM})$ in hypoxia for $24 \mathrm{~h}$. Glucose uptake was analyzed by immunofluorescence and the images were taken at $\times 200$ magnification (scale bar: $50 \mu \mathrm{m}) \mathbf{h}$; glucose consumption was analyzed by kits $\mathbf{i}$; lactate production was analyzed by kits $\mathbf{j}$; mRNA and protein levels of HK2 and Glut1 were analyzed by Q-PCR and western blotting, respectively $\mathbf{k}$. Data were expressed as means \pm SEM of three independent experiments. ${ }^{*} P<0.05,{ }^{* *} P<0.01$ vs. Normal group; ${ }^{\$} P<0.05,{ }^{\$ \$} P<0.01$ vs. NOR (30 $\left.\mu M\right)$ group

of SUV39H1 (Fig. 6b). However, the further pulse-chase experiment indicated that NOR facilitated the turnover of SUV39H1 protein (Fig. 6c). These findings suggested that NOR regulated the expression of SUV39H1 by a posttranscriptional mechanism.

The degradation of SUV39H1 is via the ubiquitinproteasomal pathway and MG-132 (a proteasome inhibitor) is employed. As shown in Fig. 6d, MG-132 $(5 \mu \mathrm{M})$ restored NOR-reduced protein level of SUV39H1 in $\mathrm{CD}_{4}{ }^{+} \mathrm{T}$ cells under hypoxic microenvironment. Furthermore, NOR $(3,10,30 \mu \mathrm{M})$ and TCDD $(5 \mathrm{nM})$ significantly increased the polyubiquitination level of SUV39H1 (Fig. 6e). In addition, EX-527 (a specific SIRT1 inhibitor; $1 \mu \mathrm{M})$, HK2 plasmid, CH223191 $(10 \mu \mathrm{M})$, and siAhR-3 prevented NOR-reduced protein level of SUV39H1 in CD4 ${ }^{+} \mathrm{T}$ cells under hypoxic microenvironment (Fig. 6f-h).

\section{H3K9me3 modification has a crucial role in NOR-enhanced Treg polarization in hypoxia}

SUV39H1 is a major member of histone KMTs and catalyzes the H3K9me3 modification, which is associated with transcription repression of Foxp $3^{34}$. In Fig. 7a, NOR $(3,10,30 \mu \mathrm{M})$ and TCDD $(5 \mathrm{nM})$ significantly reduced the global level of $\mathrm{H} 3 \mathrm{~K} 9 \mathrm{me} 3$ in $\mathrm{CD} 4^{+} \mathrm{T}$ cells under hypoxic microenvironment. Furthermore, histone modification at 

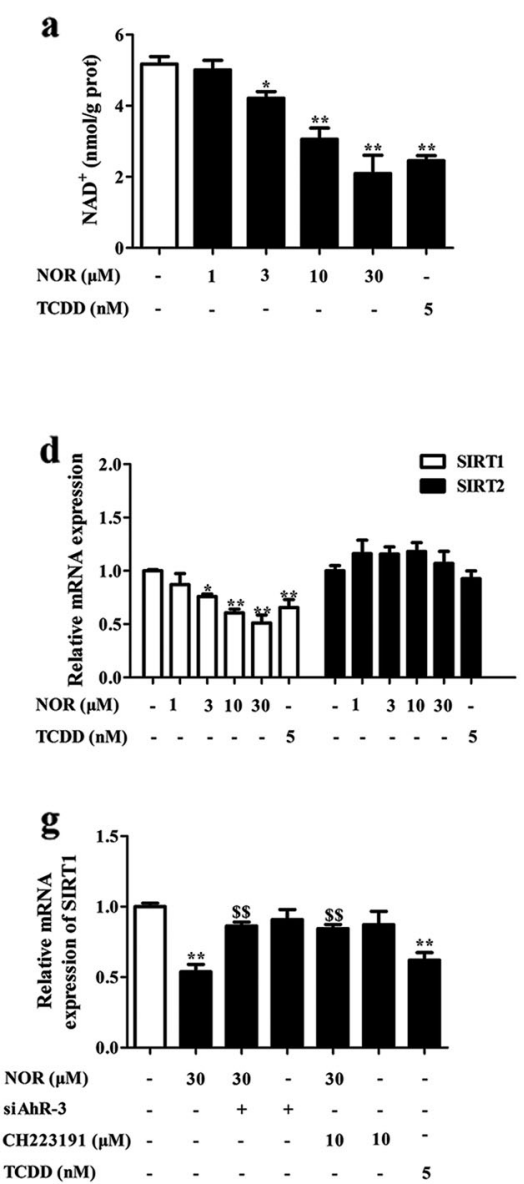
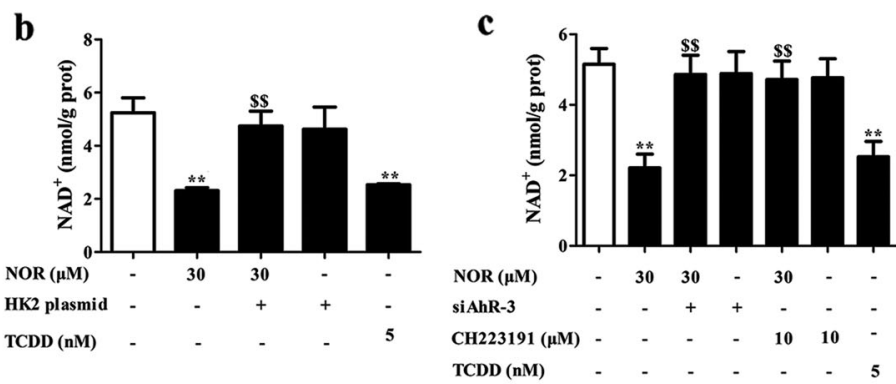

$\mathbf{e}$
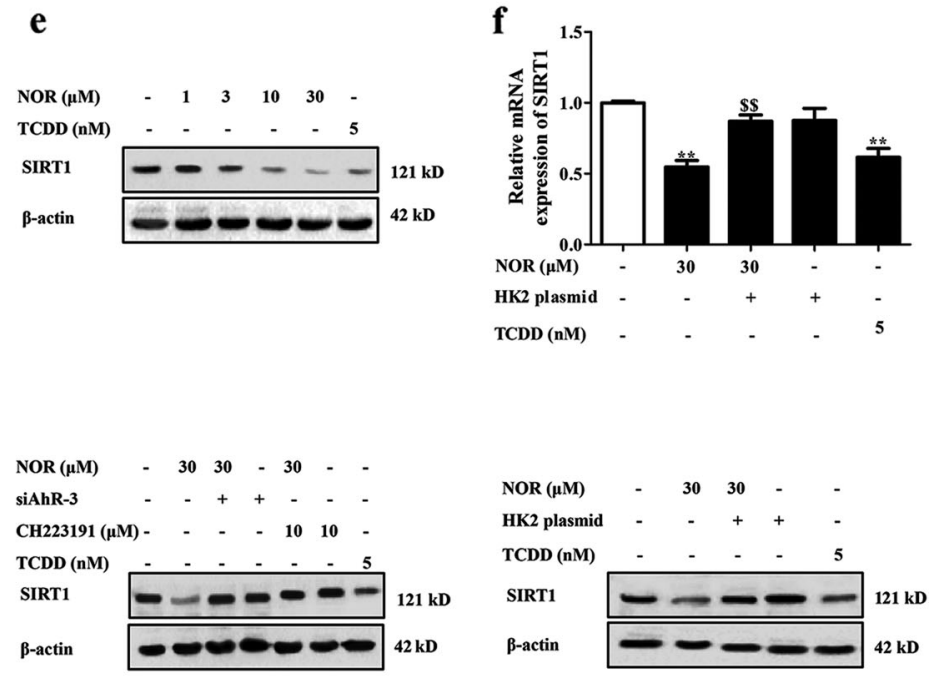

Fig. 5 NOR decreases NAD ${ }^{+}$and SIRT1 levels in $\mathrm{CD}^{+}{ }^{+}$cells under hypoxic microenvironment. a CD4 ${ }^{+} \mathrm{T}$ cells were cultured with anti-CD3/ CD28 $(2 \mu \mathrm{g} / \mathrm{ml})$, NOR $(1,3,10,30 \mu \mathrm{M})$, and TCDD $(5 \mathrm{nM})$ in hypoxia for $48 \mathrm{~h}$, and NAD level was analyzed by using kits. b, c CD4 ${ }^{+}$T cells were pretreated with $\mathrm{CH} 223191(10 \mu \mathrm{M})$ for $2 \mathrm{~h}$ or transfected with HK2 plasmid/siAhR-3, followed with incubation of anti-CD3/CD28 (2 $\mu \mathrm{g} / \mathrm{ml}), \mathrm{NOR}(1,3$, 10, $30 \mu \mathrm{M})$, and TCDD $(5 \mathrm{nM})$ in hypoxia for $48 \mathrm{~h}$. NAD ${ }^{+}$level was analyzed by using kits. $\mathbf{d}$, e CD4 ${ }^{+} \mathrm{T}$ cells were cultured with anti-CD3/CD28 $(2 \mu \mathrm{g} / \mathrm{ml})$, $\operatorname{NOR}(1,3,10,30 \mu \mathrm{M})$, and TCDD $(5 \mathrm{nM})$ in hypoxia for $48 \mathrm{~h}$. The mRNA levels of SIRT1 and 2 were analyzed by Q-PCR $\mathbf{d}$; the protein level of SIRT1 was analyzed by western blotting e. f, $\mathbf{g}$ CD4 ${ }^{+}$T cells were pretreated with $\mathrm{CH} 223191(10 \mu \mathrm{M})$ for $2 \mathrm{~h}$ or transfected with HK2 plasmid/siAhR-3, followed with incubation of anti-CD3/CD28 $(2 \mu \mathrm{g} / \mathrm{ml})$, NOR $(30 \mu \mathrm{M})$ and TCDD $(5 \mathrm{nM})$ in hypoxia for $48 \mathrm{~h}$. The mRNA and protein levels of SIRT1 were analyzed by Q-PCR and western blotting, respectively. Data were expressed as means \pm SEM of three independent experiments. ${ }^{*} P<0.05{ }^{* * *} P<0.01$ vs. Normal group; ${ }^{\$} P<0.05,{ }^{\$ \$} P<0.01$ vs. NOR $(30 \mu \mathrm{M})$ group

conserved non-coding sequences (CNSs) including CNS1, 2, and 3, and promoter of Foxp3 loci is important for the expression of Foxp $3^{35}$. NOR and TCDD significantly decreased the enrichment of H3K9me3 at Foxp3 promoter and CNS2 regions, and the decrease was more prominent at Foxp3 promoter (Fig. 7b).

In order to investigate which motif at Foxp3 promoter was influenced by NOR and TCDD, seven pairs primers at Foxp3 promoter region were designed, and chromatin immunoprecipitation (ChIP) assay was performed. $\operatorname{NOR}(3,10,30 \mu \mathrm{M})$ and TCDD $(5 \mathrm{nM})$ effectively reduced the H3K9me3 modification at $-1,201$ to $-1,500$ region of Foxp3 promoter (Fig. 7c). More importantly, significant differences existed in NOR-promoted Treg differentiation (Fig. 7d), expressions of Foxp3 and IL-10
(Supplementary Figure $7 \mathrm{a}$ and b) between cells transfected with wild-type Foxp3 promoter (WT) or - 1,201 to $-1,500$ region deletion Foxp3 promoter mutant (mut) plasmid. Further studies indicated that NOR-reduced enrichment of $\mathrm{H} 3 \mathrm{~K} 9 \mathrm{me} 3$ at $-1,201$ to $-1,500$ region of Foxp3 promoter was reversed by EX-527 $(1 \mu \mathrm{M})$, HK2 plasmid, $\mathrm{CH} 223191 \quad(10 \mu \mathrm{M})$, and siAhR-3 (Fig. $7 \mathrm{e}-\mathrm{g}$ ).

NOR drives Treg cells abundance to alleviate colitis in mice via modulating AhR/glycolysis axis and subsequent $\mathrm{NAD}^{+}$/ SIRT1/SUV39H1/H3K9me3 signaling pathway

The effective form for the anti-colitis action of NOR was verified via oral (i.g.) and intra-rectal (p.r.) administration. On the whole, i.g. and p.r. administration of NOR $(40 \mathrm{mg} /$ 


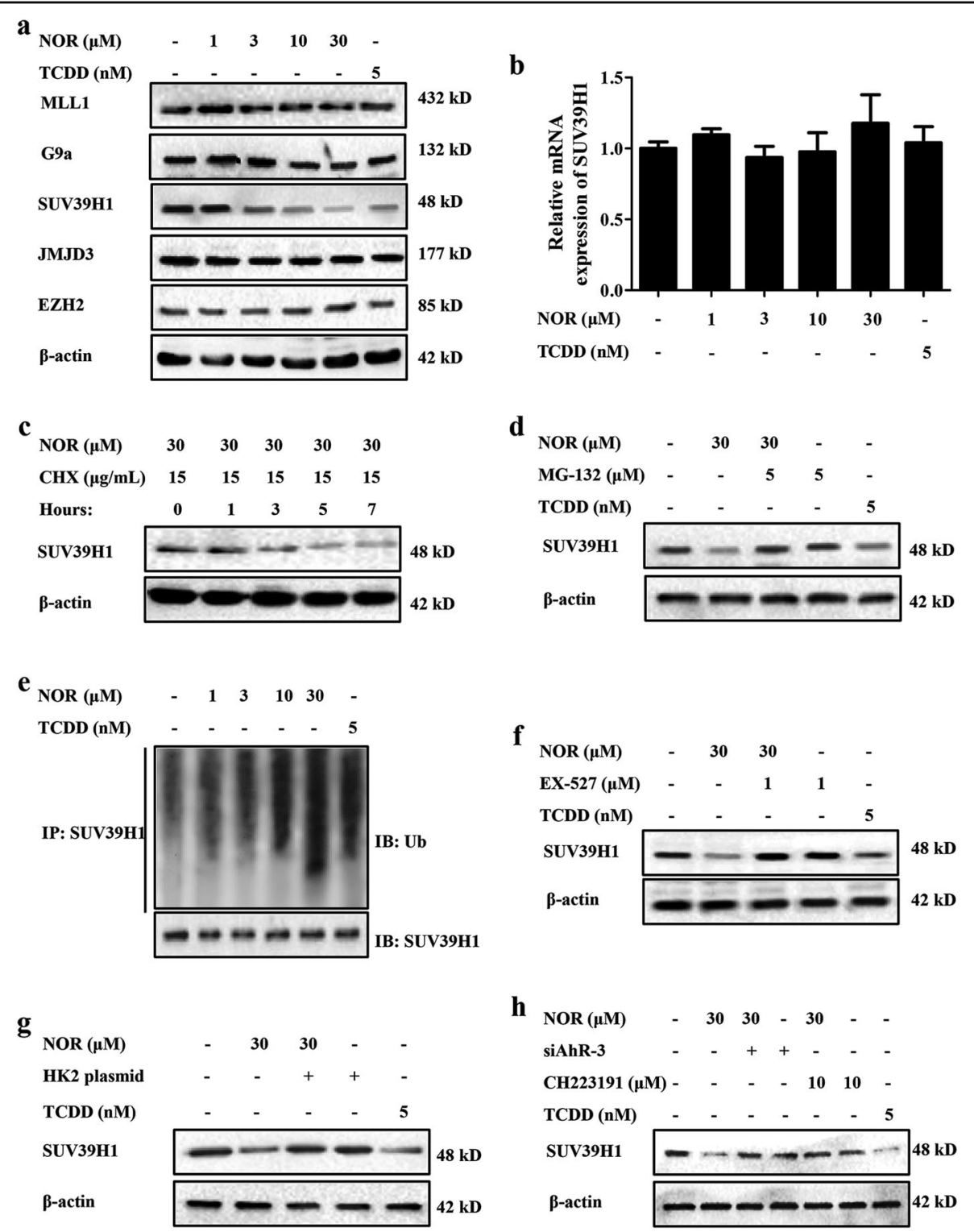

Fig. 6 NOR facilitates the ubiquitin-proteasomal degradation of SUV39H1 protein in $\mathrm{CD}^{+}{ }^{+}$cells under hypoxic microenvironment. a-c $\mathrm{CD}^{+} \mathrm{T}$ cells were cultured with anti-CD3/CD28 $(2 \mu \mathrm{g} / \mathrm{ml})$, NOR $(1,3,10,30 \mu \mathrm{M})$, and TCDD $(5 \mathrm{nM})$ in hypoxia for $48 \mathrm{~h}$. The protein levels of MLL1, G9a, SUV39H1, JMJD3, and EZH2 were analyzed by western blotting $\mathbf{a}$; the mRNA level of SUV39H1 was analyzed by Q-PCR $\mathbf{b}$; the turnover of SUV39H1 protein was analyzed by pulse-chase experiment $\mathbf{c}$. $\mathbf{d}$ CD4 ${ }^{+} \mathrm{T}$ cells were cultured with anti-CD3/CD28 ( $\left.2 \mu \mathrm{g} / \mathrm{ml}\right)$, MG132 $(5 \mu \mathrm{M}), \mathrm{NOR}(30 \mu \mathrm{M})$, and TCDD ( $5 \mathrm{nM})$ in hypoxia for $48 \mathrm{~h}$, and the protein level of SUV39H1 was analyzed by western blotting. e CD4 ${ }^{+}$T cells were cultured with anti-CD3/ CD28 $(2 \mu \mathrm{g} / \mathrm{ml})$, NOR $(1,3,10,30 \mu \mathrm{M})$, and TCDD $(5 \mathrm{nM})$ in hypoxia for $48 \mathrm{~h}$, and the ubiquitination level of SUV39H1 was analyzed. $\mathbf{f}-\mathbf{h}$ CD4 ${ }^{+}$T cells were pretreated with EX-527 (1 $\mu \mathrm{M}) / \mathrm{CH} 223191(10 \mu \mathrm{M})$ for $2 \mathrm{~h}$ or transfected with HK2 plasmid/siAhR-3, followed with incubation of anti-CD3/CD28 $(2 \mu \mathrm{g} / \mathrm{ml})$, NOR $(30 \mu \mathrm{M})$, and $(5 \mathrm{nM})$ in hypoxia for $48 \mathrm{~h}$. The protein level of SUV39H1 was analyzed by western blotting. Data were expressed as means \pm SEM of three independent experiments

kg) effectively ameliorated colitis in mice and elevated percentages of Treg cells in colons, suggesting that the prototype of NOR was the effective form for its anti-colitis action (Fig. 8a-m).

The correlation between activation of AhR, repression of glycolysis, regulation of $\mathrm{NAD}^{+} / \mathrm{SIRT} 1 / \mathrm{SUV} 39 \mathrm{H} 1 /$
H3K9me3 signals, induction of Treg cells, and eventual anti-colitis effect of NOR were validated by using $\mathrm{CH} 223191$ and HK2 plasmid. CH223191 $(10 \mathrm{mg} / \mathrm{kg})$ counteracted NOR ( $40 \mathrm{mg} / \mathrm{kg}$; i.g.)-induced enhancement of CYP1A1 expression and suppressed expressions of Glut1 and HK2 in colons (Fig. 8a, b). Furthermore, NOR 


\section{b}

a

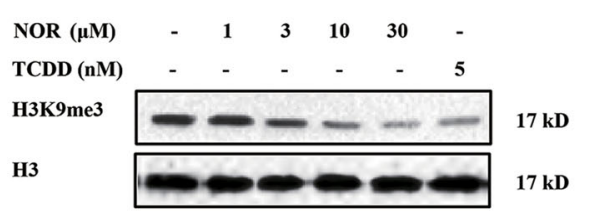

c
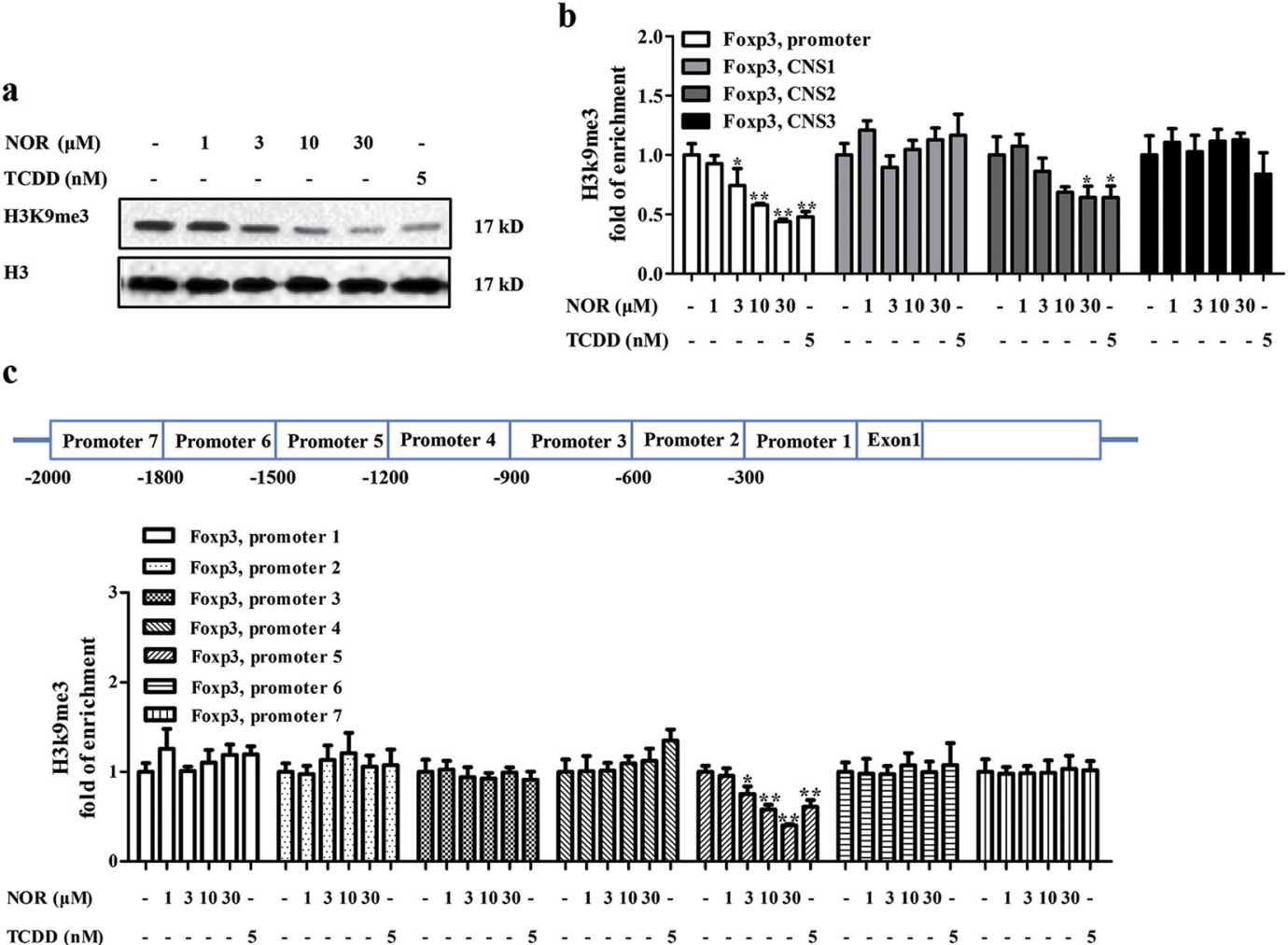

d
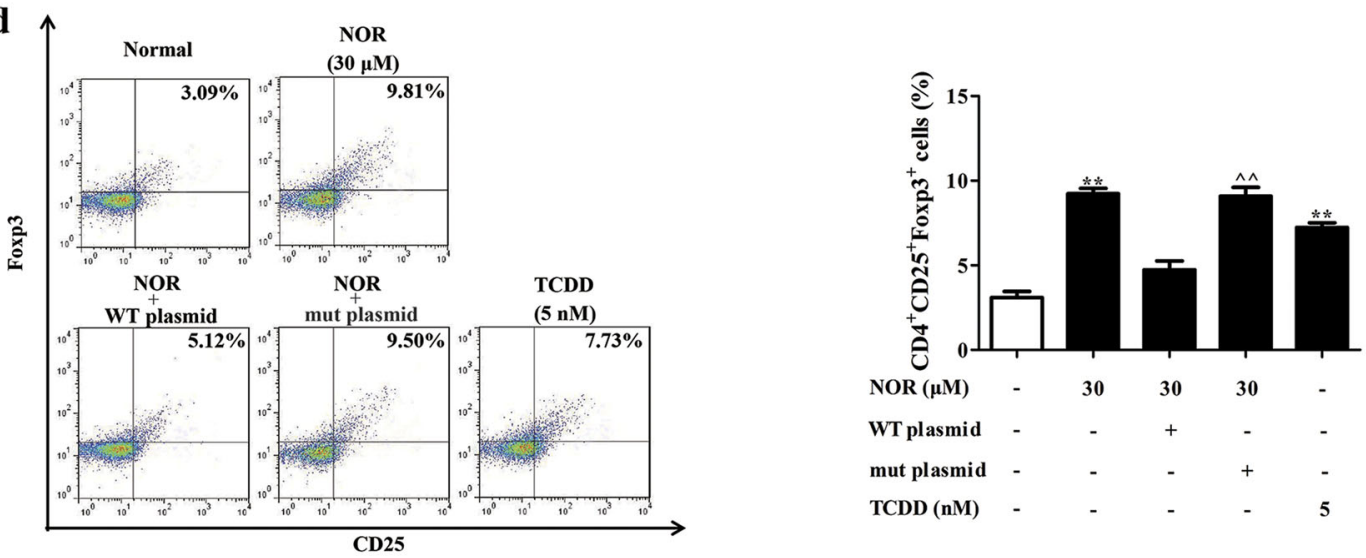

e

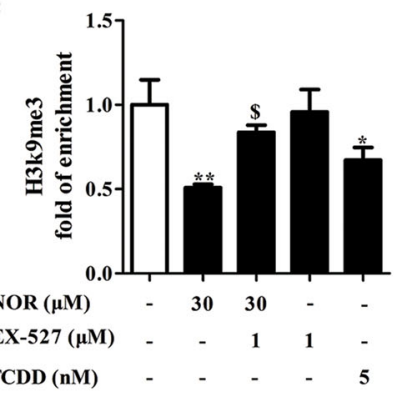

f

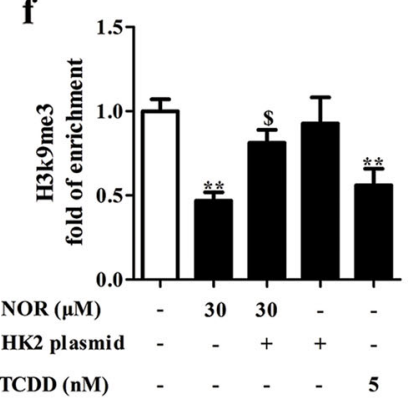

g

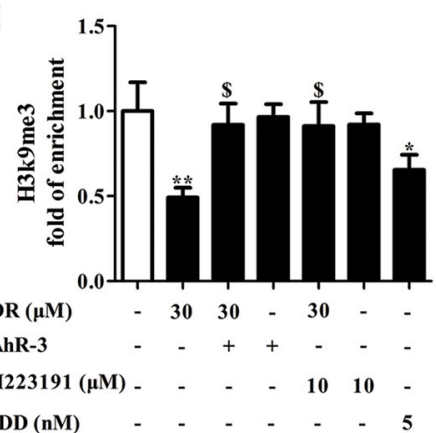

Fig. 7 (See legend on next page.) 
$\left(40 \mathrm{mg} / \mathrm{kg}\right.$; i.g.) remarkably reduced levels of $\mathrm{NAD}^{+}$, SIRT1, SUV39H1, and H3K9me3 in colons, which was prevented by $\mathrm{CH} 223191(10 \mathrm{mg} / \mathrm{kg})$ and HK2 plasmid $(10$ $\mu g)$ (Fig. 8c, d). CH223191 (10 mg/kg) and HK2 plasmid $(10 \mu \mathrm{g})$ also abolished NOR $(40 \mathrm{mg} / \mathrm{kg}$; i.g.)-elevated percentages of Treg cells and expressions of Foxp3, IL-10 in colons (Fig. 8e-g). Eventually, the anti-colitis action of NOR ( $40 \mathrm{mg} / \mathrm{kg}$; i.g.) was counteracted by CH223191 (10 $\mathrm{mg} / \mathrm{kg})$ and $\mathrm{HK} 2$ plasmid $(10 \mu \mathrm{g})$, evidenced by detection of body weight change, disease activity index (DAI) scores, colon length, myeloperoxidase (MPO) activity, histological changes, and levels of TNF- $\alpha$ and IL- $1 \beta$ in colons (Fig. 8h-m).

\section{Discussion}

NOR, a natural AhR agonist, yielded excellent amelioration of colitis and accompanied with elevated percentages of Treg cells ${ }^{17}$. However, the deeply mechanisms remain unclear. Under UC condition, colon is the main lesion tissue and undergoes a dramatic hypoxia, which is resulted from an increased metabolic demand of resident and infiltrating inflammatory cells. However, the hypoxic microenvironment of colonic mucosa under UC condition was ignored by many scholars, which is important for Treg differentiation. Therefore, we established the model of Treg differentiation in hypoxia and explored mechanisms from the angle of AhR activation and hypoxia-related miRs and glycolysis. Strikingly, NOR promoted Treg differentiation in hypoxia and normoxia. Furthermore, the minimum effective concentration was lower and the effect was stronger at the same concentration in hypoxia relative to normoxia. In addition, NOR was demonstrated with well AhR activation in $\mathrm{CD}^{+} \mathrm{T}$ cells under hypoxic microenvironment and the deeper mechanisms were investigated in the following study.

Hypoxia leads to a variety of biological changes that help cells to adopt to the low oxygen microenvironment. MiRs are small noncoding RNA molecules and intrinsic miR-31 expression in $\mathrm{CD}_{11 \mathrm{~b}^{+}} \mathrm{DCs}$ is increased under hypoxic microenvironment ${ }^{4}$; DIM and I3C decrease $m i R-31, m i R-219$, and $m i R-490$ expressions in draining lymph nodes of mice with delayed-type hypersensitivity ${ }^{7}$. At present, different from the classic AhR agonists, NOR repressed mRNA expression of $m i R-31$ but miR-31 mimic exerted little effect on NOR-enhanced Treg polarization. In addition, cellular energy metabolism also appears reprograming in hypoxia and glycolysis holds the dominant position. The glycolysis is stronger in liver cancer cells, HeLa cells, and in Saccharomyces cerevisiae under hypoxic microenvironment, and blocking it increases frequencies of Treg cells in vitro and in vivo ${ }^{8,36,37}$. In addition, AhR activation can suppress the process of glycolysis. TCDD disturbs glycolytic pathway by inhibiting the expression of GAPDH, diclofenac disturbs the activity and transcription of $\mathrm{LDH}$ in three-spined sticklebacks exposed to hypoxia, and prior polychlorinated biphenyl (PCB) suppresses expressions of glycolytic enzymes in fundulus heteroclitus. Notably, all the actions of TCDD, diclofenac, and PCB are mediated by inhibiting formation of HIF-1 $\alpha /$ ARNT complexes ${ }^{38-40}$. Similar to TCDD, NOR significantly repressed glycolysis by reducing the formation of HIF-1 $\alpha /$ ARNT complexes and downregulating the expression of HK2, and HK2 plasmid almost completely reversed NOR-promoted Treg differentiation in hypoxia. These findings emphasized the involvement of glycolysis in NOR-enhanced Treg polarization under hypoxic microenvironment.

Increasing evidence indicates that increased glycolysis results in upregulated level of $\mathrm{NAD}^{+}$in cells, as $\mathrm{LDH}$ could catalyze the concomitant interconversions of $\mathrm{NADH}$ to $\mathrm{NAD}^{+}$, thereby increasing cellular $\mathrm{NAD}^{+}$ level ${ }^{22}$. In addition, $\mathrm{NAD}^{+}$determines the fate of Treg cells; exogenous $\mathrm{NAD}^{+}$promotes the conversion of Treg into Th17 cells in vitro, in the absence of TGF- $\beta$, IL- 6 , and IL-23, and in the presence of IL- ${ }^{23}$. Furthermore, NAD ${ }^{+}$ is the substrate and agonist for SIRTs and SIRT1 could deacetylate three novel target sites including K31, K262, and K267 in Foxp3 protein ${ }^{41}$. Treatment with EX-527 promotes expression of Foxp3 during the progress of iTreg differentiation ${ }^{25}$; adoptive transfer of $\mathrm{CD} 4^{+} \mathrm{CD} 25^{-}$Foxp3 ${ }^{-}$Teff cells lacking SIRT1 to B6/ $\operatorname{Rag} 1^{-/}$mice results in higher percentages of Treg cells

\footnotetext{
(see figure on previous page)

Fig. 7 H3K9me3 modification has an important role in NOR-induced Treg differentiation under hypoxic microenvironment. a-c CD4 $4^{+} \mathrm{T}$ cells were cultured with anti-CD3/CD28 $(2 \mu \mathrm{g} / \mathrm{ml})$, NOR $(1,3,10,30 \mu \mathrm{M})$, and TCDD $(5 \mathrm{nM})$ in hypoxia for $48 \mathrm{~h}$. The global level of H3K9me3 was analyzed by western blotting $\mathbf{a}$; the enrichment of $\mathrm{H} 3 \mathrm{~K} 9 \mathrm{me} 3$ in Foxp3 promoter, CNS1, 2, and 3 regions was analyzed by ChIP $\mathbf{b}$; the enrichment of H3K9me3 in -1 to -300 (Foxp3 promoter 1), -301 to -600 (Foxp3 promoter 2), -601 to -900 (Foxp3 promoter 3), -901 to $-1,200$ (Foxp3 promoter 4), 1,201 to $-1,500$ (Foxp3 promoter 5), - 1,501 to $-1,800$ (Foxp3 promoter 6 ), and - 1,801 to $-2,000$ (Foxp3 promoter 7) regions was analyzed by ChIP c. $\mathbf{d} C D 4^{+} \mathrm{T}$ cells were transfected with bacterial-contained wild-type Foxp3 promoter (WT) or - 1,201 to $-1,500$ region deletion mutant (mut) plasmid, followed with incubation of anti-CD3/CD28 $(2 \mu \mathrm{g} / \mathrm{ml})$, NOR $(30 \mu \mathrm{M})$, and TCDD $(5 \mathrm{nM})$ in hypoxia for $72 \mathrm{~h}$, and frequencies of Treg cells were analyzed by flow cytometry. e- $\mathbf{g}$ CD4 ${ }^{+} \mathrm{T}$ cells were pretreated with EX-527 $(1 \mu \mathrm{M}) / \mathrm{CH} 223191(10 \mu \mathrm{M})$ for $2 \mathrm{~h}$ or transfected with HK2 plasmid/siAhR-3, followed with anti-CD3/CD28 $(2 \mu \mathrm{g} / \mathrm{ml})$, NOR $(30 \mu \mathrm{M})$ in hypoxia for $48 \mathrm{~h}$. The enrichment of H3K9me3 at $-1,201$ to $-1,500$ region of Foxp3 promoter was analyzed by ChIP. Data were expressed as means \pm SEM of three independent experiments. ${ }^{*} P<0.05,{ }^{* *} P<0.01$ vs. Normal group; ${ }^{\$} P<$ 0.05 vs. NOR $(30 \mu \mathrm{M})$ group. ${ }^{\wedge} P<0.01$ vs. NOR + WT plasmid group
} 
a

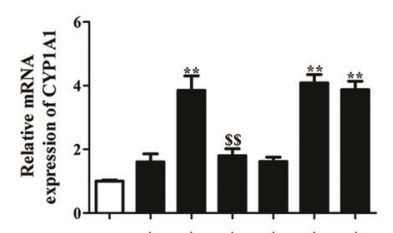

DSS

NOR $(\mathrm{mg} / \mathrm{kg} ; \mathrm{i} . \mathrm{g}$ )

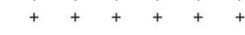

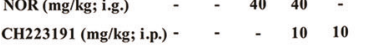

$\operatorname{TCDD}(\mu \mathrm{g} / \mathrm{kg} ;$ i.p. $)$

NOR (mg/kg; p.r.)

b
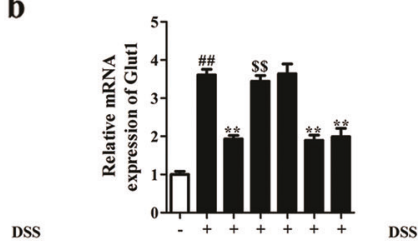

DSS

NOR (mg/kg; i.g.)

CH223191 (mg/kg:

$\operatorname{TCDD}(\mu \mathrm{g} / \mathrm{kg}$; i.p.) - - - - 25 - 25 TCDD $(\mu \mathrm{g} / \mathrm{kg}$; i.p. $) \quad-\quad-\quad 25$ -

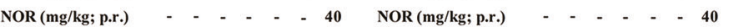

c

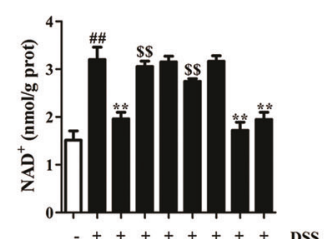

d

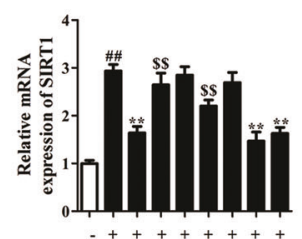

DSS

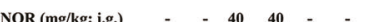

CH223191 (mg/kg; i.p.) - $\quad-\quad \begin{array}{llllll} & 10 & 10 & - & -\end{array}$

$\operatorname{TCDD}(\mu \mathrm{g} / \mathrm{kg} ; \mathrm{i.p.})$

NOR (mg/kg; p.r.)

CYP1A1

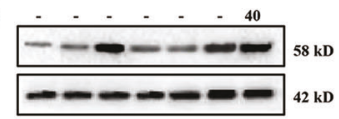

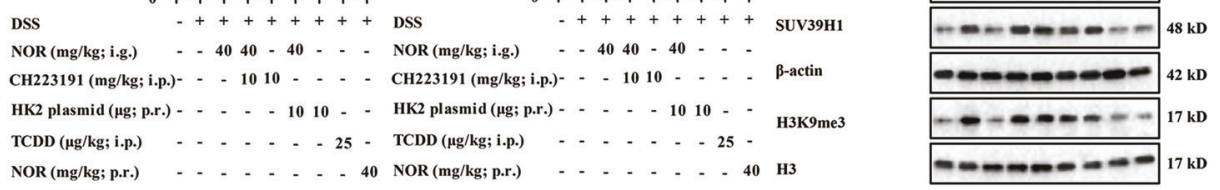

DSS $\quad-++++++$

$\mathrm{CH} 223191$ (mg/kg; i.p.) - - $\quad-1010 \quad-$

$\operatorname{TCDD}(\mu \mathrm{g} / \mathrm{kg}$; i.p.) $\quad$ - $\quad-\quad-\quad-\quad-25$ -

NOR (mg/kg; p.r.)

Glut1

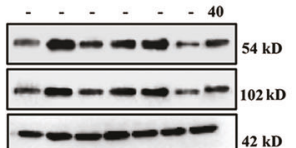

B-actin

$42 \mathrm{kD}$
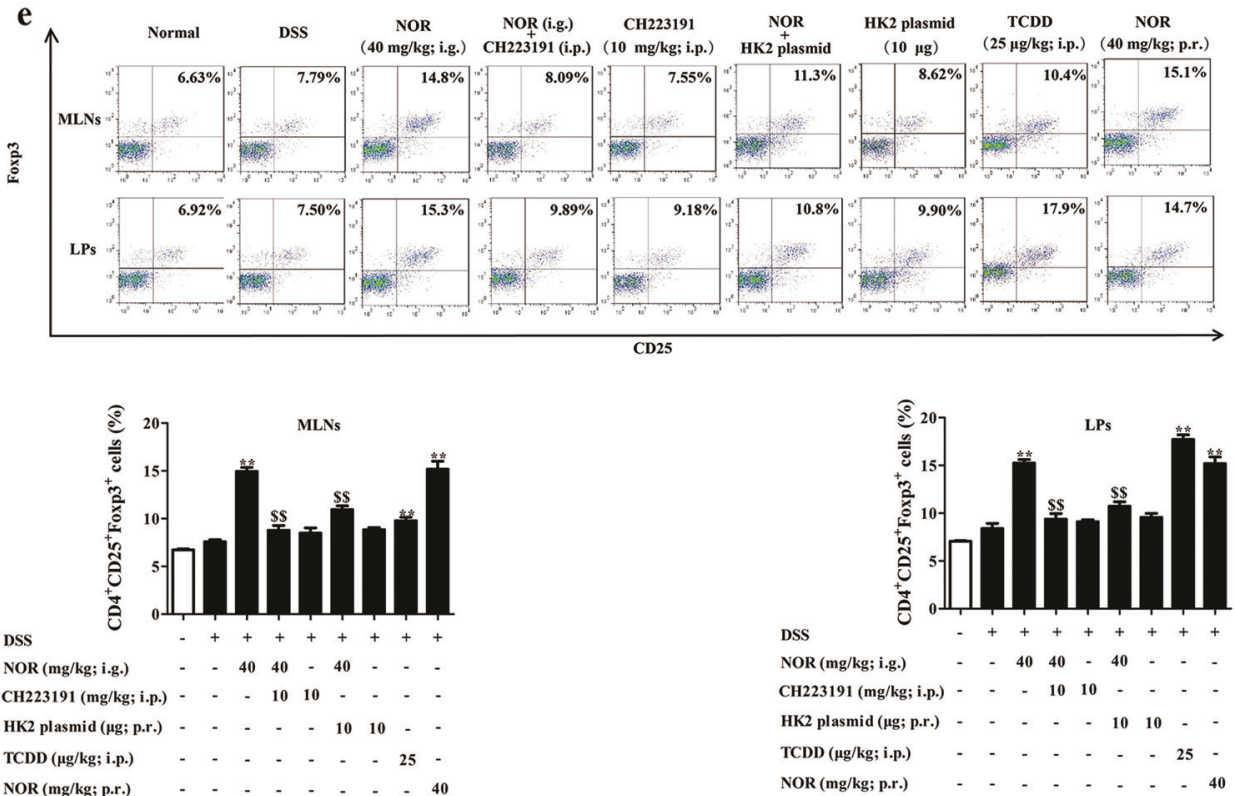

Fig. 8 (See legend on next page.) 


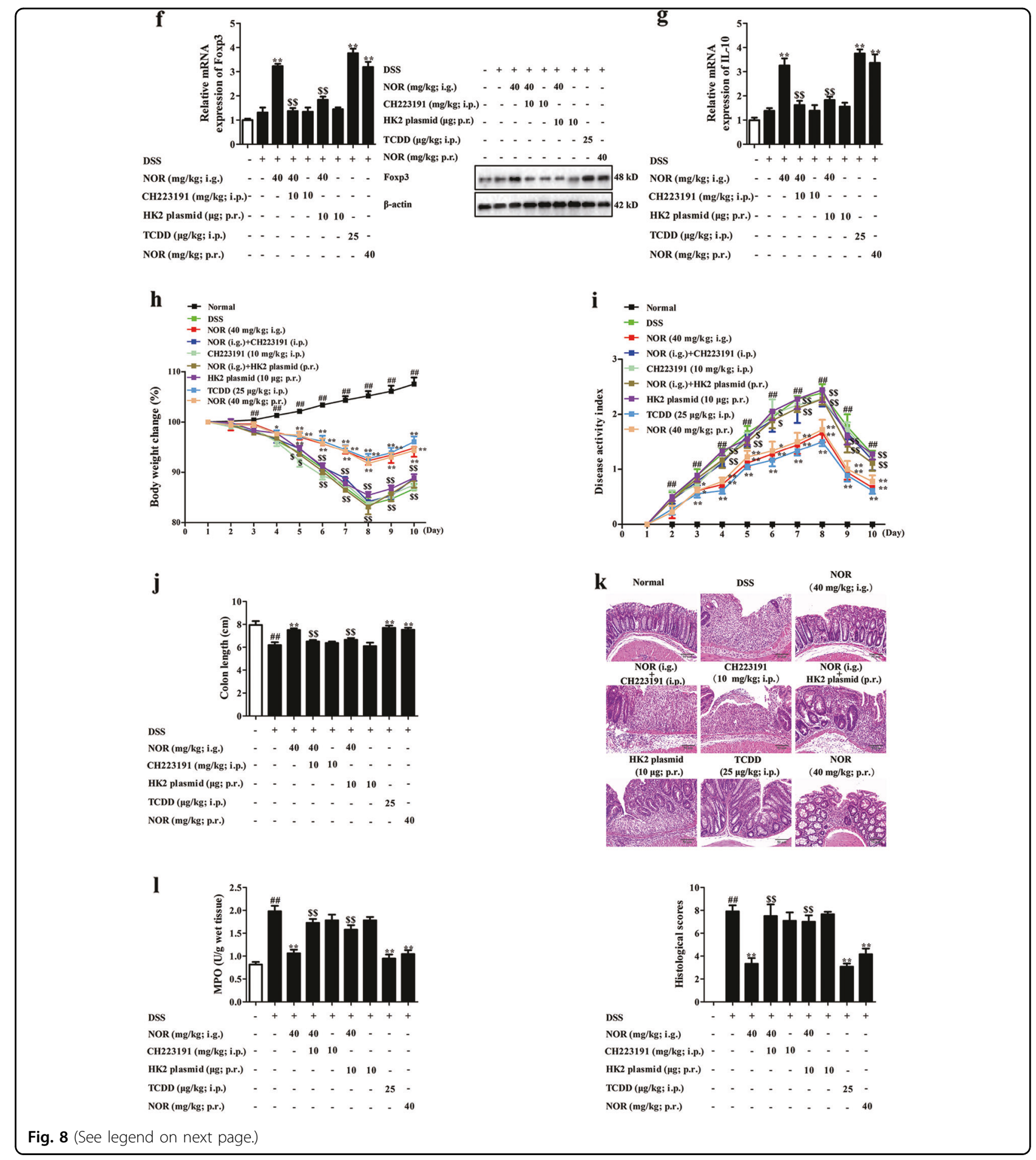

compared with mice receiving WT Teff cells and subsequent attenuation of colitis ${ }^{42}$. Similar to TCDD, NOR remarkably decreased levels of $\mathrm{NAD}^{+}$and SIRT1 in $\mathrm{CD}_{4}^{+}$ $\mathrm{T}$ cells under hypoxic condition, which could be prevented by $\mathrm{HK} 2$ plasmid, $\mathrm{CH} 223191$, and siAhR-3. However, NOR boosted both mRNA and protein expressions of Foxp3 in CD4 ${ }^{+} \mathrm{T}$ cells, indicating that SIRT1 might not be the final signal molecule for NOR-induced Treg differentiation in hypoxia.

It should be noted that SIRT1 can regulate the protein levels of histone KMTs and histone KDMs. Aguilar-Arnal and colleagues. ${ }^{26}$ indicate that SIRT1 interacts with MLL1 

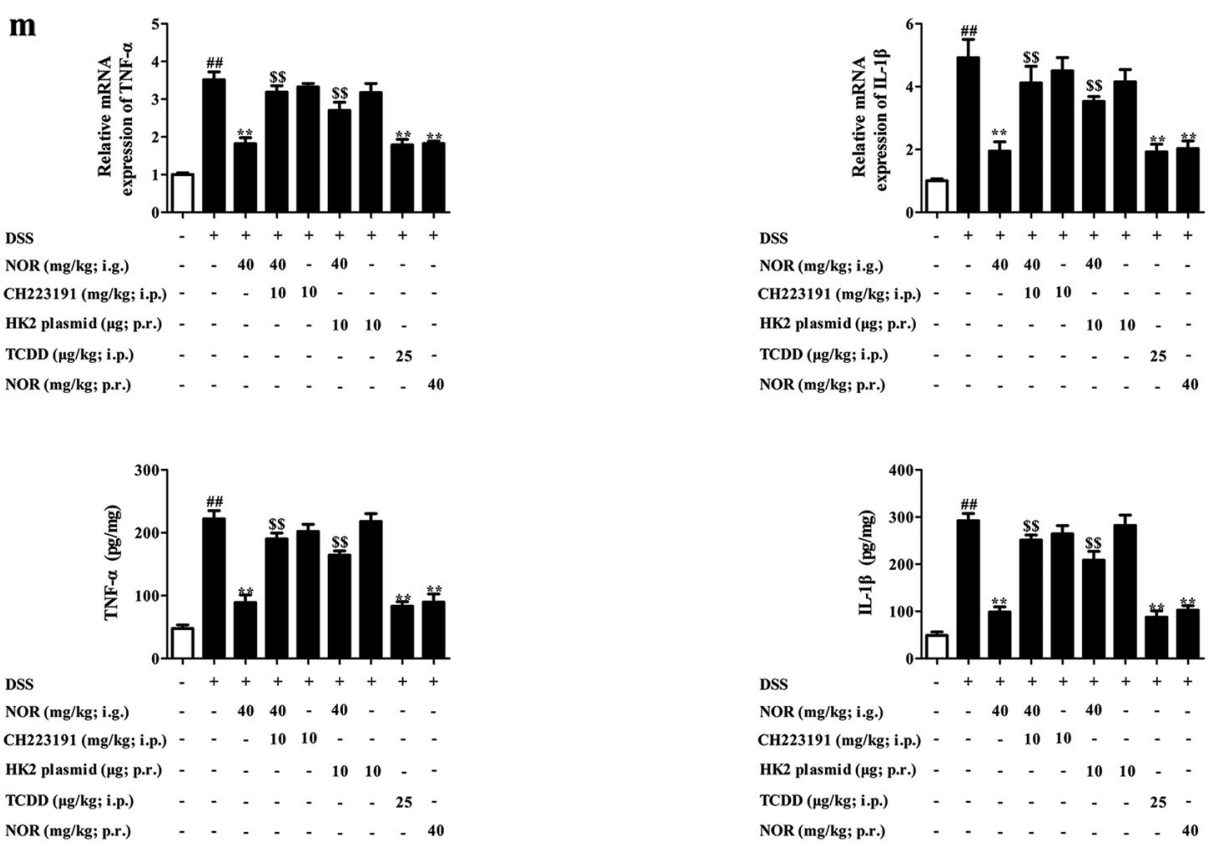

Fig. 8 NOR drives Treg cells abundance to alleviate colitis in mice via modulating AhR/glycolysis axis and subsequent NAD $/$ SIRT1/ SUV39H1/H3K9me3 signaling pathway. Mice were fed with 2.5\% DSS for 7 days and followed by 3 days of drinking water alone. TCDD ( $25 \mu \mathrm{g} / \mathrm{kg} ; \mathrm{i}$. p.) was administered once on day 1, whereas NOR (40 mg/kg; i.g. and p.r.), CH223191 (10 mg/kg; i.p.), and HK2 plasmid (10 $\mu$ g; p.r.) were administered for 10 days. a The mRNA and protein levels of CYP1A1 in colons were analyzed by Q-PCR and western blotting, respectively. b The mRNA and protein levels of HK2 and Glut1 in colons were analyzed by Q-PCR and western blotting. c The level of NAD ${ }^{+}$in colons was analyzed by kits. $\mathbf{d}$ The mRNA level of SIRT1 in colons was analyzed by Q-PCR; the protein levels of SIRT1, SUV39H1, and H3K9me3 in colons were analyzed by western blotting. e The frequencies of Treg cells in mesenteric lymph nodes (MLNs) and colonic lamina proprias (LPs) were analyzed by flow cytometry. $\mathbf{f}$ The mRNA and protein levels of Foxp3 in colons were analyzed by Q-PCR and western blotting, respectively. $\mathbf{g}$ The mRNA expression of IL-10 in colons was analyzed by Q-PCR. $\mathbf{h}$ Body weight change was analyzed. i Disease activity index (DAl) scores were calculated. $\mathbf{j}$ Colon length was analyzed. $\mathbf{k}$ Histopathological changes of colons were analyzed by H\&E staining and the images were taken at $\times 200$ magnification (scale bar: $50 \mu \mathrm{m})$. I Myeloperoxidase (MPO) activity was analyzed by kits. $\mathbf{m}$ The mRNA and protein levels of TNF- $a$ and IL-1 $1 \beta$ were analyzed by Q-PCR and ELISA. Data were expressed as means \pm SEM of six mice in each group. ${ }^{\# \#} P<0.01$ vs. Normal group; ${ }^{*} P<0.05$ and ${ }^{* *} P<0.01$ vs. DSS group; ${ }^{\$} P<0.05$ and ${ }^{\$ \$} P<0.01 \mathrm{vs}$. NOR (40 mg/kg; i.g.) group

and mediates the deacetylation of MLL1 at two conserved residues, termed K1130 and K1133; Bosch-Presegué and colleagues. $^{27}$ demonstrate that SIRT1 inhibits MDM2 polyubiquitination of lysine 87 in the chromodomain of SUV39H1; Zhao and colleagues $^{28}$ report that SIRT1 knockdown increases EZH2 acetylation, resulting in enhanced stability. Furthermore, expressions of histone KMTs and histone KDMs are altered in hypoxia. MLL1, G9a, SUV39H1, JMJD3, and EZH2 expressions are increased in glioblastoma multiforme, breast cancer cell, and human fetal lung epithelial cells under hypoxic microenvironment, respectively ${ }^{29-33}$. More importantly, they have been demonstrated to participate in Treg differentiation. For example, deficiency of G9A promotes Treg differentiation and results in attenuation of colitis induced by $\mathrm{T}$-cell transfer ${ }^{43-46}$. After performing screening experiments for MLL1, G9a, SUV39H1, JMJD3, and EZH2, we found that NOR only reduced the protein level of SUV39H1 by regulating its ubiquitin-proteasomal degradation and the action was mediated by AhR/glycolysis/SIRT1 signals.

SUV39H1 is the Su (var) 3-9, Enhancer-of-zeste, Trithorax domain-containing histone KMT and participates in H3K9me3 modification. Lacking of SUV39H1 has significant defects in H3K9me3 level and SUV39H1 contributes to facultative heterochromatin formation and gene silencing via elevating H3K9me3 modification ${ }^{34}$. Knockdown of SUV39H1 restores the E-cadherin expression by blocking H3K9me3 modification ${ }^{47}$. Depletion of SUV39H1 or chaetocin (a specific inhibitor of SUV39H1) increases the mRNA expression of BZLF1 in B95-8 cells by reducing the enrichment of H3K9me3 at BZLF1 promoter ${ }^{48}$. Furthermore, the histone modification at promoter, CNS1, 2, and 3 regions can regulate the expression of Foxp $3^{35}$. At present, NOR actually decreased the global level of $\mathrm{H} 3 \mathrm{~K} 9 \mathrm{me} 3$ and inhibited 
enrichment of H3K9me3 at $-1,201$ to $-1,500$ region of Foxp3 promoter; all these effects were reversed by EX527, HK2 plasmid, CH223191, and siAhR-3. Then, the causal link between activation of AhR, reduction of glycolysis, regulation of $\mathrm{NAD}^{+} / \mathrm{SIRT} 1 / \mathrm{SUV} 39 \mathrm{H} 1 /$ H3K9me3 signals, induction of Treg cells, and alleviation of colitis by NOR was confirmed in mice with colitis. Finally, the path for NOR-mediated Treg differentiation and anti-colitis action was fully sketched out.

In conclusion, NOR promoted Treg differentiation and then carried out anti-UC action by regulating AhR/glycolysis axis and subsequent $\mathrm{NAD}^{+} / \mathrm{SIRT} 1 / \mathrm{SUV} 39 \mathrm{H} 1 /$ H3K9me3 signaling pathway.

\section{Materials and methods}

\section{Chemicals and reagents}

NOR (purity $>98 \%$ ) was isolated and purified from Radix Linderae and the structure was identified by comparison of its spectral data (UV, IR, MS, ${ }^{1} \mathrm{H}$-, and ${ }^{13} \mathrm{C}$ NMR) with the literature data ${ }^{49}$; TCDD was purchased from J\&K Chemical (Beijing, China); DSS (molecular weight $36000-50000 \mathrm{kDa}$ ) was purchased from MP Biomedical (Aurora, USA); CH223191 was purchased from Selleckchem (Houston, USA); FITC-anti-CD4, APC-antiCD25, PE-anti-Foxp3, and purified anti-mouse CD3/ CD28 mAbs were purchased from eBioscience (San Diego, USA); 3-[4,5-dimetylthiazol-2-yl]-2,5-diphenyltetrazolium bromide (MTT) and 2-NBDG were purchased from Invitrogen Corp. (Carlsbad, USA); RPMI 1640 was purchased from Gibco BRL (Grand Island, USA); fetal bovine serum (FBS) was purchased from Sijiqing (Hangzhou, China); antibodies against HK2 and Glut1 were purchased from Sangon Biotech (Shanghai, China); Peroxidase-conjugated secondary antibodies, protein A $+\mathrm{G}$ agarose, and cell counting kit-8 (CCK-8) were purchased from Bioworld Technology, Inc. (Georgia, USA); antibodies against AhR, ARNT, HSP90, and Foxp3 were purchased from Santa Cruz Biotechnology (CA, USA); antibodies against SIRT1, SUV39H1, HIF-1 $\alpha$, and H3K9me3 were purchased from Abcam (Cambridge, UK); phenylmethanesulfonyl fluoride (PMSF) and nuclear and cytoplasmic protein extraction kit was purchased from KeyGen Biotech (Nanjing, China); HiScript QRTSuperMix and AceQ qPCR SYBR Green Master Mix were purchased from Vazyme Biotech (Piscataway, USA); mouse IL- $1 \beta$ and TNF- $\alpha$ enzyme-linked immunosorbent assay kits were purchased from Dakewe Biotech (Shenzhen, China); MPO kit was purchased from Jiancheng Biotech (Nanjing, China); ChIP assay kit was purchased from Beyotime Biotechnology (Shanghai, China); siAhR13 was purchased from Genechem (Shanghai, China); HK2 plasmid, WT plasmid, mut plasmid, and pGL3-XRE reporter gene plasmid were purchased from Jiman (Shanghai, China); Bulgen-loop miRNA quantitative reverse-transcriptase PCR Primer Sets specific for $m i R-31$, $m i R-219$ and $m i R-490$, NC mimic, and $m i R-31$ mimic were purchased from RiboBio (Guangzhou, China); and Entranster in vivo transfection reagent was purchased from Engree Biosystems Co. (Beijing, China). Other chemical products used were of the analytical grade.

\section{Animals}

Female C57BL/6 mice, weighting 18-22 g (6-8 weeks old), were provided by the Comparative Medicine Center of Yangzhou University (Yangzhou, China). They were housed with free access to food and water under a $12 \mathrm{~h}$ light: $12 \mathrm{~h}$ dark cycle in plastic cages at $25 \pm 2{ }^{\circ} \mathrm{C}$ with a relative humidity of $45 \pm 10 \%$. The animal experiments were strictly performed in accordance with the Guide for the Care and Use of Laboratory Animals. The protocol was approved by the Animal Ethics Committee of China Pharmaceutical University.

\section{Induction, drug administration, and assessment of UC}

Mice were fed with $2.5 \%$ DSS for 7 days and followed by 3 days of drinking water alone. NOR $(40 \mathrm{mg} / \mathrm{kg})$ was i.g. or p.r. administered daily for consecutive 10 days; TCDD $(25 \mu \mathrm{g} / \mathrm{kg})$ was intraperitoneally (i.p.) administered only at day 1; CH223191 (10 mg/kg) was i.p. administered daily for consecutive 10 days; HK2 plasmid was mixed with equal volume Entranster in vivo transfection reagent, and p.r. administrated daily for consecutive 10 days. To identify the involvement of AhR and glycolysis in NORattenuated colitis, mice were randomly divided into nine groups as follows: normal group, DSS group, NOR (40 $\mathrm{mg} / \mathrm{kg}$, i.g.) group, NOR (40 mg/kg, i.g.) +CH223191 (10 $\mathrm{mg} / \mathrm{kg}$, i.p.) group, $\mathrm{CH} 223191$ (10 mg/kg, i.p.) group, NOR ( $40 \mathrm{mg} / \mathrm{kg}$, i.g. $)+$ HK2 plasmid (10 $\mu$ g, p.r.) group, HK2 plasmid (10 $\mu$ g, p.r.) group, TCDD $(25 \mu \mathrm{g} / \mathrm{kg}$, i.p.) group, and NOR (40 mg/kg, p.r.) group.

Body weight, stool consistency, and the presence of gross blood were observed every day. The DAI was calculated as the mean value of body weight loss, stool consistency, and gross bleeding. In addition, the colons were collected and photographed on day 10 . The distal was fixed in $10 \%$ formalin for histopathological examination and scores were calculated by assessing the inflammation severity, extent of injury, and crypt damage as previously described ${ }^{17}$.

\section{Cell culture}

$\mathrm{CD}_{4}^{+} \mathrm{T}$ cells were isolated from mesenteric lymph nodes (MLNs) of C57BL/6 mice and purified with magnetic beads according to the manufacturer's instructions (Miltenyi Biotech, Cologne, Germany). They were maintained in complete RPMI 1640 medium supplemented with $100 \mathrm{U} / \mathrm{ml}$ of streptomycin, $100 \mathrm{U} / \mathrm{ml}$ of penicillin, and 10\% FBS under hypoxic (supplied 
with $2 \%$ oxygen) or normoxic (supplied with $21 \%$ oxygen) microenvironment.

\section{Cell viability assay}

$\mathrm{CD}^{+} \mathrm{T}$ cells were seeded into 96-well plates and treated with $\operatorname{NOR}(0.1,0.3,1,3,10,30,60,100 \mu \mathrm{M})$ in hypoxia or normoxia for $68 \mathrm{~h}$. Subsequently, MTT ( 5 $\mathrm{mg} / \mathrm{ml}, 20 \mu \mathrm{l})$ or CCK-8 solution $(10 \mu \mathrm{l})$ were added and cells were continuously incubated for an additional $4 \mathrm{~h}$. For MTT assay, the supernatants were removed, formazan crystals were dissolved in $200 \mu \mathrm{l}$ dimethyl sulfoxide, and optical absorbance at $570 \mathrm{~nm}$ was read by a Microplate Reader (Thermo, Waltham, MA, USA). For CCK- 8 assay, the supernatants were retained and optical density absorbance at $450 \mathrm{~nm}$ was read by a Microplate Reader.

\section{Flow cytometry}

Lymphocytes were harvested from in vitro culture or isolated from MLNs and colonic lamina proprias. The method for lymphocytes isolation was performed as described in our previous study ${ }^{17}$. Subsequently, they were stained with FITC-anti-CD4 and APC-anti-CD25 antibodies for $30 \mathrm{~min}$ at $4{ }^{\circ} \mathrm{C}$, followed by fixation and permeabilization for $5 \mathrm{~h}$. Then, they were stained with PEanti-Foxp3 antibody for another $1 \mathrm{~h}$, washed with fluorescence-activated cell sorting staining buffer, and analyzed by BD FACS Calibur (BD Biosciences, San Jose, USA). All the results were analyzed by using Flowjo 7.6 software (Treestar, Ashland, OR).

\section{Differentiation of Treg cells}

$\mathrm{CD} 4{ }^{+} \mathrm{T}$ cells were treated with anti-CD3/CD28 $(2 \mu \mathrm{g} /$ $\mathrm{ml})$, NOR $(1,3,10,30 \mu \mathrm{M})$, and TCDD $(5 \mathrm{nM})$ under hypoxic or normoxic condition for $72 \mathrm{~h}$. The frequencies of Treg cells were detected by using flow cytometry.

\section{Transfection}

For stable transfection: $\mathrm{CD} 4^{+} \mathrm{T}$ cells were transfected with lentivirus-mediated siAhR1-3 for $72 \mathrm{~h}$ according to the manufacturer's protocols ${ }^{50}$. For transient transfection: $\mathrm{CD}^{+} \mathrm{T}$ cells were transfected with HK2 plasmid, miR-31 mimic, WT plasmid, and mut plasmid by using Lipofectamine 2000 (Invitrogen Corp.) for $24 \mathrm{~h}$ according to the manufacturer's protocols ${ }^{51}$.

\section{Quantitative PCR}

Total RNA was isolated from cultured cells or colons by TRIzol extraction reagent according to the manufacturer's instructions (Invitrogen Corp.). Subsequently, RNA ( $2 \mu \mathrm{g}$ ) was reversed transcribed into cDNA by using HiScript QRTSuperMix. The cDNA template $(2 \mu \mathrm{l})$ was added to the $20 \mu \mathrm{PCR}$ reaction, which contained sequence-specific primers and the AceQ qPCR SYBR Green Master Mix reagent. The cycling conditions included an initial step at $95^{\circ} \mathrm{C}$ for $5 \mathrm{~min}$, followed by 40 cycles at $95^{\circ} \mathrm{C}$ for $10 \mathrm{~s}$ and $55-60^{\circ} \mathrm{C}$ for $30 \mathrm{~s}$. The primers were listed in Supplementary Table 1.

\section{Immunofluorescence}

$\mathrm{CD}^{+} \mathrm{T}$ cells were treated with anti-CD3/CD28 $(2 \mu \mathrm{g} /$ $\mathrm{ml}), \operatorname{NOR}(1,3,10,30 \mu \mathrm{M})$, and TCDD $(5 \mathrm{nM})$ in hypoxia or normoxia for $48 \mathrm{~h}$, fixed with $4 \%$ paraformaldehyde for $30 \mathrm{~min}$, and permeabilized with $0.2 \%$ Triton- 100 for 20 min. Subsequently, they were blocked with $5 \%$ bovine serum albumin for $2 \mathrm{~h}$ and incubated with anti-Foxp3 antibody $(1: 150)$ at $4{ }^{\circ} \mathrm{C}$ for overnight. After being washed with phosphate-buffered saline (PBS), cells were stained with rhodamine-conjugated affinipure goat antimouse IgG antibody $(1: 100)$ for $2 \mathrm{~h}$. Subsequently, coverslips were stained with 4', 6-diamidino-2-phenylindole for $20 \mathrm{~min}$ and images were captured by using Olympus IX53 (Olympus, Tokyo, Japan).

\section{Cellular uptake of NOR}

$\mathrm{CD} 44^{+} \mathrm{T}$ cells were treated with anti-CD3/CD28 $(2 \mu \mathrm{g} /$ $\mathrm{ml})$, NOR $(30 \mu \mathrm{M})$ in hypoxia for $4 \mathrm{~h}$, and lysed in water by three freeze-thaw cycles followed by centrifugation at 5,000 r.p.m. for $10 \mathrm{~min}$. The supernatants were transferred to the centrifuge tube and $1 \mathrm{ml}$ acetonitrile was added to extract NOR. The extracts were centrifugated at 12000 r.p.m. for $10 \mathrm{~min}$ and the upper organic phase was all carefully transferred to $2 \mathrm{ml}$ EP tube. After being dried for $2 \mathrm{~h}, 100 \mu \mathrm{l}$ mobile phase was added into the tube, which were centrifugated at 12000 r.p.m. for $10 \mathrm{~min}$. Finally, the supernatants were transferred to 2 $\mathrm{ml}$ brown glass vials and an aliquot of $5 \mu \mathrm{l}$ was injected for LC-MS analysis.

An ACQUITY UPLC BEH C18 $(2.1 \times 100$ mm I.D., 1.7 $\mu \mathrm{m}$, Waters, Milford, MA, USA) column was used for the analyses. The mobile phase composed of A ( $0.1 \%$ formic acid, $\mathrm{v} / \mathrm{v}$ ) and $\mathrm{B}$ (acetonitrile) with a gradient elution: $0-5$ min, 90-70\% A; 5-7 min, 70-0\% A; 7-9 min, 0\% A; and 10 $\mathrm{min}, 90 \% \mathrm{~A}$. The flow rate of the mobile phase was $0.4 \mathrm{ml} /$ min. All data collected in centroid mode were acquired by using Masslynx V4.1 software (Waters); post-acquisition quantitative analysis was performed by using the QuanLynx program (Waters Corp.). The linear range of NOR in plasma was $10-10,000 \mathrm{ng} / \mathrm{ml}$ and the limit of quantification for NOR was $10 \mathrm{ng} / \mathrm{ml}$.

\section{Glucose uptake}

$\mathrm{CD}^{+} \mathrm{T}$ cells were treated with anti-CD3/CD28 $(2 \mu \mathrm{g} /$ $\mathrm{ml}), \operatorname{NOR}(1,3,10,30 \mu \mathrm{M})$, and TCDD $(5 \mathrm{nM})$ in hypoxia or normoxia for $24 \mathrm{~h}$. After starvation for $4 \mathrm{~h}$, cells were supplied with 2-NBDG $(500 \mu \mathrm{M})$ and intracellular fluorescence intensity was photographed by using Olympus IX53 as the uptake of glucose. 


\section{XRE-luciferase reporter gene}

$\mathrm{CD}^{+} \mathrm{T}$ cells were transiently transfected with pGL3XRE reporter gene vector and renilla luciferase vector by using Lipofectamine 2000. After transfection for $\sim 24 \mathrm{~h}$, the media was removed and the cells were treated with NOR $(1,3,10,30 \mu \mathrm{M})$ and TCDD $(5 \mathrm{nM})$ in hypoxia for an additional $24 \mathrm{~h}$. Subsequently, the luciferase reporter activity was measured by using Dual-Luciferase Reporter Assay System (Promega, WI, USA). Briefly, cells were lysed and transferred into 96-well plates. Approximately $100 \mu \mathrm{l}$ luciferase substrate was added into each well and the absorbance was detected by using a Microplate Reader.

\section{Western blotting}

\section{For total protein extraction}

Cells or colons were lysed by using NP40 buffer containing $1 \mathrm{mM}$ PMSF on ice for $15 \mathrm{~min}$ and centrifuged at 12000 r.p.m. for $10 \mathrm{~min}$, and then supernatants were collected. For histone extraction: cells or colons were lysed by using stronger RIPA lysis buffer containing $1 \mathrm{mM}$ PMSF on ice for $15 \mathrm{~min}$ and centrifugated at 12000 r.p.m. for $10 \mathrm{~min}$ at $4{ }^{\circ} \mathrm{C}$. The supernatants were discarded and precipitation in $200 \mu \mathrm{l}$ of $0.25 \mathrm{M} \mathrm{HCl}$ was resuspended on a rotator at $4{ }^{\circ} \mathrm{C}$ for overnight. Then, the cocktails were centrifuged at 12000 r.p.m. for $10 \mathrm{~min}$ at $4{ }^{\circ} \mathrm{C}$ and supernatants were neutralized with an appropriate volume of $\mathrm{NaOH}$.

The total protein and histone at equal amount were separated by SDS-polyacrylamide gel electrophoresis (PAGE). Then, they were transferred onto the polyvinylidene difluoride (PVDF) membranes (Millipore, Billerica, MA), which were blocked with $9 \%$ (w/v) non-fat milk for $2 \mathrm{~h}$ at room temperature. Subsequently, PVDF membranes were incubated with specific primary antibodies at $4{ }^{\circ} \mathrm{C}$ for overnight. After being washed for three times, they were further incubated with horseradish peroxidase-conjugated secondary antibody for $2 \mathrm{~h}$ at $37^{\circ}$ C. Lastly, the bands were visualized by using ECL plus reagent.

\section{Co-immunoprecipitation}

$\mathrm{CD}^{+} \mathrm{T}$ cells were treated with anti-CD3/CD28 $(2 \mu \mathrm{g} /$ $\mathrm{ml})$, NOR $(1,3,10,30 \mu \mathrm{M})$, and TCDD $(5 \mathrm{nM})$ in hypoxia for $24 \mathrm{~h}$. Subsequently, they were lysed with stronger RIPA lysis buffer for $15 \mathrm{~min}$ and centrifuged at 12000 r.p. $\mathrm{m}$. for $5 \mathrm{~min}$. The supernatants were collected and incubated with $1 \mu \mathrm{g}$ antibody against AhR or IgG at $4{ }^{\circ} \mathrm{C}$ for overnight, followed by the addition of $20 \mu \mathrm{l}$ protein A/G agarose beads at $4{ }^{\circ} \mathrm{C}$ for $4 \mathrm{~h}$. Afterwards, the cocktails were centrifuged at 5,000 r.p.m. for $10 \mathrm{~min}$ and immunoprecipitates were washed with stronger RIPA lysis buffer for four times. The immunoprecipitated proteins were separated by SDS-PAGE gel and western blotting was performed with the indicated antibodies.

\section{Measurement of cellular $\mathrm{NAD}^{+}$level}

$\mathrm{CD}^{+} \mathrm{T}$ cells were treated with anti-CD3/CD28 $(2 \mu \mathrm{g} /$ $\mathrm{ml})$, NOR $(1,3,10,30 \mu \mathrm{M})$, and TCDD $(5 \mathrm{nM})$ in hypoxia for $48 \mathrm{~h}$. Subsequently, they were washed by using icecold PBS for three times and incubated with $\mathrm{NAD}^{+}$ extraction buffer, which were provided by the manufacturer (AAT Bioquest, CA, USA). Then, cells were centrifuged at 1,000 r.p.m. at $4{ }^{\circ} \mathrm{C}$ for $10 \mathrm{~min}$ and the supernatants were collected. Approximately $50 \mu \mathrm{l}$ test sample was added into each well and the absorbance was read at $575 \pm 5 \mathrm{~nm}$ by a Microplate Reader.

\section{Chromation immunoprecipitation}

$\mathrm{CD}_{4}^{+} \mathrm{T}$ cells were treated with anti-CD3/CD28 $(2 \mu \mathrm{g} /$ $\mathrm{ml})$, NOR $(1,3,10,30 \mu \mathrm{M})$, and TCDD $(5 \mathrm{nM})$ in hypoxia for $48 \mathrm{~h}$. Subsequently, they were incubated with $1 \%$ formaldehyde for $10 \mathrm{~min}$ at room temperature for crosslinking. The reaction was quenched with $125 \mathrm{mM}$ glycine and cells were pelleted and washed with ice-cold PBS. The cell pellets were resuspended in SDS lysis buffer supplemented with PMSF. The cocktails were then sonicated (amplitude, $40 \mathrm{w}$; process time, $6 \mathrm{~min}$; ON time, $4.5 \mathrm{~s}$; OFF time, $9 \mathrm{~s}$ ) to shear the DNA and extracts were clarified by centrifugation at 12000 r.p.m. for $10 \mathrm{~min}$ at $4{ }^{\circ} \mathrm{C}$. The supernatants were collected and $\sim 1 \%$ of the total sheared chromatin was set aside and served as Input control. After being precleared by protein A+G Agarose/Salmon Sperm DNA beads, antibody against $\mathrm{H} 3 \mathrm{~K} 9 \mathrm{me} 3$ was added and incubated with the extracts on a rotator at $4{ }^{\circ} \mathrm{C}$ for overnight. No-antibody controls were always included as the negative control. Then, protein A+G Agarose/Salmon Sperm DNA beads were added and the beads containing protein-DNA complexes were collected. Subsequently, they were washed with low-salt wash buffer, high-salt wash buffer, $\mathrm{LiCl}$ wash buffer, and TE buffer to remove nonspecific sequences, and eluted in elution buffer $(1 \%$ SDS, $0.1 \mathrm{M} \mathrm{NaHCO}_{3}$ ). Finally, de-crosslinking was performed with $5 \mathrm{M} \mathrm{NaCl}$ and heated at $65^{\circ} \mathrm{C}$ for $4 \mathrm{~h}$. The DNA enrichment was established with Q-PCR and the primers used were listed in Supplementary Table 1.

\section{Statistical analysis}

Data were presented as the means \pm SEM. Statistical analysis was performed by PASW statistics 19 software (SPSS, Inc., Chicago, IL). Statistical differences were assessed by one-way analysis of variance test. A value of $P<0.05$ $(P<0.05)$ were accepted as a significant difference.

\section{Acknowledgements}

This work was supported by the Natural Science Foundation of Jiangsu Province of China (No. BK20140662), the Program of the National Natural Science Foundation of China (No. 81503319), the University Innovation Research and Training Program of China Pharmaceutical University (G14067), and partially supported by the Priority Academic Program Development of Jiangsu Higher Education Institutions. 


\section{Author contributions}

Z.F.W. and Y.D. designed the study. Q.L., K.W., S.M.Q., Y.L., and Y.R.X. performed all the experiments. In addition, Q.L. prepared the manuscript, which were reviewed and approved by all authors.

\section{Competing interest}

The authors declare no competing financial interests.

\section{Publisher's note}

Springer Nature remains neutral with regard to jurisdictional claims in published maps and institutional affiliations.

Supplementary Information accompanies this paper at (https://doi.org/ 10.1038/s41419-018-0297-3).

Received: 20 November 2017 Revised: 9 January 2018 Accepted: 9 January 2018

Published online: 15 February 2018

\section{References}

1. Lee, J. H., Elly, C., Park, Y. \& Liu, Y. C. E3 ubiquitin ligase VHL regulates hypoxiainducible factor-1a to maintain regulatory $T$ cell stability and suppressive capacity. Immunity 42, 1062-1074 (2015).

2. Hsiao, H. W. et al. Deltex1 antagonizes HIF-1a and sustains the stability of regulatory T cells in vivo. Nat. Commun. 6, 6353 (2015).

3. Dang, E. V. et al. Control of $\mathrm{T}(\mathrm{H}) 17 / \mathrm{T}$ (reg) balance by hypoxia-inducible factor 1. Cell 146, 772-784 (2011).

4. Pyfferoen, $L$. et al. The transcriptome of lung tumor-infiltrating dendritic cells reveals a tumor-supporting phenotype and a microRNA signature with negative impact on clinical outcome. Oncoimmunology 6, e1253655 (2016).

5. Xu, Q. et al. MicroRNA-1296 inhibits metastasis and epithelial-mesenchymal transition of hepatocellular carcinoma by targeting SRPK1-mediated PI3KAKT pathway. Mol. Cancer 16, 103 (2017).

6. Chinen, l. et al. The aryl hydrocarbon receptor/microRNA-212/132 axis in $T$ cells regulates $\mathrm{IL}-10$ production to maintain intestinal homeostasis. Int. Immunol. 27, 405-415 (2015).

7. Singh, N. P. et al. Dietary indoles suppress delayed-type hypersensitivity by inducing a switch from proinflammatory Th17 cells to anti-inflammatory regulatory $T$ cells through regulation of microRNA. J. Immunol. 196, 1108-1122 (2016)

8. Guo, W. et al. MiR-199a-5p is negatively associated with malignancies and regulates glycolysis and lactate production by targeting hexokinase 2 in liver cancer. Hepatology 62, 1132-1144 (2015).

9. Okano, T. et al. 3-bromopyruvate ameliorate autoimmune arthritis by modulating Th17/Treg cell differentiation and suppressing dendritic cell activation. Sci. Rep. 7, 42412 (2017)

10. Shi, L. Z. et al. HIFlalpha-dependent glycolytic pathway orchestrates a metabolic checkpoint for the differentiation of TH17 and Treg cells. J. Exp. Med. 208, 1367-1376 (2011)

11. Ungaro, R., Mehandru, S., Allen, P. B., Peyrin-Biroulet, L. \& Colombel, J. F. Ulcerative colitis. Lancet 389, 1756-1770 (2017)

12. Clambey, E. T. et al. Hypoxia-inducible factor-1 alpha-dependent induction of FoxP3 drives regulatory T-cell abundance and function during inflammatory hypoxia of the mucosa. Proc. Natl Acad. Sci. USA 109, E2784-E2793 (2012).

13. Karhausen, J. et al. Epithelial hypoxia-inducible factor-1 is protective in murine experimental colitis. J. Clin. Invest. 114, 1098-1106 (2004).

14. Choi, S. et al. Inflammatory hypoxia induces syndecan-2 expression through IL-1ß-mediated FOXO3a activation in colonic epithelia. FASEB J. 31, 1516-1530 (2017).

15. Wei, Z. F. et al. Norisoboldine, an anti-arthritis alkaloid isolated from Radix Linderae, attenuates osteoclast differentiation and inflammatory bone erosion in an aryl hydrocarbon receptor-dependent manner. Int. J. Biol. Sci. 11, 1113-1126 (2015)

16. Tong, B. et al. Norisoboldine ameliorates collagen-induced arthritis through regulating the balance between Th17 and regulatory T cells in gut-associated lymphoid tissues. Toxicol. Appl. Pharmacol. 282, 90-99 (2015).
17. LV, Q. et al. Norisoboldine ameliorates DSS-induced ulcerative colitis in mice through induction of regulatory T cells in colons. Int. Immunopharmacol. 29 787-797 (2015).

18. Flück, K., Breves, G., Fandrey, J. \& Winning, S. Hypoxia-inducible factor 1 in dendritic cells is crucial for the activation of protective regulatory $T$ cells in murine colitis. Mucosal Immunol. 9, 379-390 (2016).

19. Quintana, F. J. et al. Control of $T(r e g)$ and $T(H) 17$ cell differentiation by the aryl hydrocarbon receptor. Nature 453, 65-71 (2008).

20. Coffre, M. \& Koralov, S. B. miRNAs in B cell development and lymphomagenesis. Trends Mol. Med. 23, 721-736 (2017).

21. Macintyre, A. N. et al. The glucose transporter Glut1 is selectively essential for CD4 T cell activation and effector function. Cell. Metab. 20, 61-72 (2014).

22. Kaja, S., Payne, A. J., Naumchuk, Y. \& Koulen, P. Quantification of lactate dehydrogenase for cell viability testing using cell lines and primary cultured astrocytes. Curr. Protoc. Toxicol. 72, 1-2.26.10 (2017). 2.26.

23. Elkhal, $\mathrm{A}$. et al. $\mathrm{NAD}(+)$ regulates Treg cell fate and promotes allograft survival via a systemic IL-10 production that is CD4(+) CD25(+) Foxp3(+) T cells independent. Sci. Rep. 6, 22325 (2016).

24. Carafa, V. et al. Sirtuin functions and modulation: from chemistry to the clinic Clin. Epigenetics 8, 61 (2016).

25. Beier, U. H., Akimova, T., Liu, Y., Wang, L. \& Hancock, W. W. Histone/protein deacetylases control Foxp3 expression and the heat shock response of $T$ regulatory cells. Curr. Opin. Immunol. 23, 670-678 (2011).

26. Aguilar-Arnal, L., Katada, S., Orozco-Solis, R. \& Sassone-Corsi, P. NAD(+)-SIRT1 control of H3K4 trimethylation through circadian deacetylation of MLL1. Nat. Struct. Mol. Biol. 22, 312-318 (2015).

27. Bosch-Presegué, L. et al. Stabilization of Suv39H1 by SirT1 is part of oxidative stress response and ensures genome protection. Mol. Cell 42, 210-223 (2011)

28. Li, M. et al. SIRT1 antagonizes liver fibrosis by blocking hepatic stellate cell activation in mice. FASEB J. 32, 500-511 (2018)

29. Heddleston, J. M. et al. Hypoxia-induced mixed-lineage leukemia 1 regulates glioma stem cell tumorigenic potential. Cell Death Differ. 19, 428-439 (2012).

30. Casciello, F. et al. G9a drives hypoxia-mediated gene repression for breast cancer cell survival and tumorigenesis. Proc. Natl Acad. Sci. USA 114, 7077-7082 (2017)

31. Benlhabib, H. \& Mendelson, C. R. Epigenetic regulation of surfactant protein A gene (SP-A) expression in fetal lung reveals a critical role for Suv39h methyltransferases during development and hypoxia. Mol. Cell. Biol. 31, 1949-1958 (2011).

32. Lee, H. Y., Choi, K., Oh, H., Park, Y. K. \& Park, H. HIF-1-dependent induction of Jumonji domain-containing protein (JMJD) 3 under hypoxic conditions. Mol. Cells 37, 43-50 (2014).

33. Mahara, S., Chng, W. J. \& Yu, Q. Molecular switch of EZH2 in hypoxia. Cell Cycle 15, 3007-3008 (2016).

34. Shirai A. et al. Impact of nucleic acid and methylated H3K9 binding activities of Suv39h1 on its heterochromatin assembly. Elife 6, e25317 (2017). doi: 10.7554/ eLife.25317.

35. Tone, Y., Furuuchi, K., Kojima, Y., Tykocinski, M. L. \& Greene, M. I. Tone M. Smad3 and NFAT cooperate to induce Foxp3 expression through its enhancer. Nat. Immunol. 9, 194-202 (2008).

36. Zhang, Y. et al. Nucleus accumbens-associated protein-1 promotes glycolysis and survival of hypoxic tumor cells via the HDAC4-HIF-1a axis. Oncogene $\mathbf{3 6}$, 4171-4181 (2017)

37. Jin, M. et al. Glycolytic enzymes coalesce in $\mathrm{G}$ bodies under hypoxic stress. Cell Rep. 20, 895-908 (2017).

38. Chen, Y. Y. \& Chan, K. M. Transcriptional inhibition of TCDD-mediated induction of cytochrome P450 1A1 and alteration of protein expression in a zebrafish hepatic cell line following the administration of TCDD and $\mathrm{Cd} 2$. Toxicol. Lett. 282, 121-135 (2018).

39. Prokkola, J. M. et al. Hypoxia and the pharmaceutical diclofenac influence the circadian responses of three-spined stickleback. Aquat. Toxicol. 158, 116-124 (2015).

40. Kraemer, L. D. \& Schulte, P. M. Prior PCB exposure suppresses hypoxia-induced up-regulation of glycolytic enzymes in Fundulus heteroclitus. Comp. Biochem. Physiol. C Toxicol. Pharmacol. 139, 23-29 (2004).

41. Kwon, H. S. et al. Three novel acetylation sites in the Foxp3 transcription factor regulate the suppressive activity of regulatory $\mathrm{T}$ cells. J. Immunol. 188, 2712-2721 (2012)

42. Akimova, $\mathrm{T}$. et al. Targeting sirtuin-1 alleviates experimental autoimmune colitis by induction of Foxp3+T-regulatory cells. Mucosal Immunol. 7, 1209-1220 (2014). 
43. Antignano, F. et al. Methyltransferase G9A regulates $T$ cell differentiation during murine intestinal inflammation. J. Clin. Invest. 124, 1945-1955 (2014).

44. Sarmento, O. F. et al. A novel role for KLF14 in T regulatory cell differentiation. Cell Mol. Gastroenterol. Hepatol. 1, 188-202.e4 (2015).

45. Li, Q. et al. Critical role of histone demethylase Jmjd3 in the regulation of CD4 +T-cell differentiation. Nat. Commun. 5, 5780 (2014).

46. DuPage, M. et al. The chromatin-modifying enzyme Ezh2 is critical for the maintenance of regulatory $\mathrm{T}$ cell identity after activation. Immunity $\mathbf{4 2}$, 227-238 (2015).

47. Dong, C. et al. Interaction with Suv39H1 is critical for Snail-mediated E-cadherin repression in breast cancer. Oncogene 32, 1351-1362 (2013).
48. Imai, $\mathrm{K}$. et al. Role of the histone $\mathrm{H3}$ lysine 9 methyltransferase Suv39 h1 in maintaining Epsteinn-Barr virus latency in B95-8 cells. FEBS J. 281, 2148-2158 (2014).

49. Chou, G. X., Norio, N., Ma, C. M., Wang, Z. T. \& Masao, H. Isoquinoline alkaloids from Lindera aggregata. Chin. J. Nat. Med 5, 272-275 (2005).

50. Gélinas, J. F., Davies, L. A., Gill, D. R. \& Hyde, S. C. Assessment of selected media supplements to improve F/HN lentiviral vector production yields. Sci. Rep. 7, 10198 (2017).

51. Tang, F., Tang, S., Guo, X., Yang, C. \& Jia, K. CT45A1 siRNA silencing suppresses the proliferation, metastasis and invasion of lung cancer cells by downregulating the ERK/CREB signaling pathway. Mol. Med Rep. 16, 6708-6714 (2017). 